\title{
Drag Induced by Flat-Plate Imperfections in Compressible Turbulent Flow Regimes
}

\author{
Pascal Molton, $*$ David Hue,, \pm and Reynald Bur $\stackrel{\ddagger}{\sharp}$ \\ ONERA-The French Aerospace Lab, 92190 Meudon, France
}

DOI: $10.2514 / 1 . C 032911$

\begin{abstract}
This paper presents the results of a coupled experimental and numerical study aimed at evaluating the influence of typical aircraft surface imperfections on the flat-plate drag production in fully turbulent conditions. A test campaign involving high-level measurement techniques, such as microdrag evaluation, near-wall laser Doppler velocimetry, and oil-film interferometry, has been carried out at several Mach numbers from 0.5 to 1.3 to quantify the impact of a large range of flat-plate imperfections. Forward-facing and backward-facing plain and chamfered steps of different heights have been studied. A whole numerical study, based on Reynolds-averaged Navier-Stokes computations, has been completed and used for validation purposes. Given the very small order of magnitude of the forces to be measured and calculated, the relative comparison between experimental and numerical outcomes is satisfactory. Even if some local discrepancies exist, results show an overall good agreement in the positioning of the different imperfection drag productions. Such investigations are of prime interest to determine industrialization tolerances or excrescence geometries offering the best compromises between manufacturing costs and aerodynamic performances.
\end{abstract}

\section{Nomenclature}

$C_{f}=$ skin friction coefficient

$C D=$ drag coefficient

$C D_{f}=$ friction drag coefficient

$C D_{p}=$ pressure drag coefficient

$h=$ step height

$M_{0}=$ freestream Mach number

Patm = atmospheric pressure

$P_{i} \quad=$ stagnation pressure

$R e=$ freestream Reynolds number

$T_{i}=$ stagnation temperature

$U=$ velocity

$U^{+}=$normalized velocity

$U_{\tau}=$ friction velocity

$X=$ longitudinal coordinate

$Z=$ vertical coordinate

$Z^{+}=$normalized vertical coordinate

$\delta=$ boundary-layer physical thickness

$\nu \quad=$ kinematic viscosity

\section{Subscript}

$\infty$

$=$ freestream state value

\section{Introduction}

D ESPITE the fact that drag prediction has been the subject of various studies for many years, the influence of surface imperfections on the turbulent drag production is still poorly assessed. Indeed, many publications deal with the impact of excrescences on the laminar-turbulent transition [1 $1-5]$, but on the topic of drag

Presented as Paper 2013-3167 at the 43rd Fluid Dynamics Conference, San Diego, CA, 24-27 June 2013; received 25 March 2014; accepted for publication 7 May 2014; published online 20 August 2014. Copyright @ 2014 by ONERA. Published by the American Institute of Aeronautics and Astronautics, Inc., with permission. Copies of this paper may be made for personal or internal use, on condition that the copier pay the $\$ 10.00$ per-copy fee to the Copyright Clearance Center, Inc., 222 Rosewood Drive, Danvers, MA 01923; include the code 1542-3868/14 and $\$ 10.00$ in correspondence with the CCC.

*Research Engineer, Fundamental and Experimental Aerodynamics Department; pascal.molton@onera.fr.

'Research Engineer, Applied Aerodynamics Department; david.hue@ onera.fr. Member AIAA.

*Research Engineer, Fundamental and Experimental Aerodynamics Department; reynald.bur@onera.fr. penalty due to imperfections in fully turbulent conditions, the literature is not abundant. The current estimation methods are based on the use of tables, especially these available in Hoerner [6]. These data come from incompressible experimental studies conducted many years ago [7], and the accuracy and applicability of these measurements might not be satisfactory anymore.

The purpose of the present study is to evaluate in subsonic, transonic, and supersonic regimes (Mach number from 0.5 to 1.3 and Reynolds number from 2.7 to 4.1 million) the impact of surface imperfections, such as plain or chamfered steps and cavities, on the drag production of a turbulent flat plate. Such geometric disturbances are representative of the discontinuities over aircraft surfaces. Given the heights of the steps considered here and the boundary-layer thicknesses in the different wind-tunnel conditions, the ratio $h / \delta$ varies from approximately 5 to $30 \%$ in this study.

Concerning the experimental part of the study, the objective is to determine by three measurement techniques the drag levels and the skin friction coefficients induced by the surface imperfections. The tests include microforce measurements with a three-component balance, boundary-layer profile measurements by laser Doppler velocimetry (LDV), and oil-film interferometry methods. These techniques have been performed on a classical flat plate to be compared with reference results before being applied to the plates exhibiting the different imperfections.

The numerical part included the realization of structured grids and two-dimensional (2-D) Reynolds-averaged Navier-Stokes (RANS) computations focused on the imperfections studied experimentally. The computational fluid dynamics (CFD) calculations have been performed with an in-house aerodynamic code (second-order accuracy). The sensitivity to turbulence models has been evaluated.

At first, the present paper gives a description of the experimental setup and geometries. Then, the different measurement techniques are presented and evaluated. In a second time, the numerical procedure is described. Afterward, an in-depth analysis of the experimental and CFD results is given. Finally, general conclusions and prospects are proposed.

\section{Experimental Test Setup and Geometries: Measurement Techniques}

\section{A. Experimental Test Setup and Geometries}

The experimental investigations were conducted in a wind tunnel named S8Ch. It belongs to the Fundamental and Experimental Aerodynamics Department of ONERA-The French Aerospace Lab (Meudon, France). This facility is an Eiffel model that can generate subsonic, transonic, and supersonic flows in continuous conditions. 


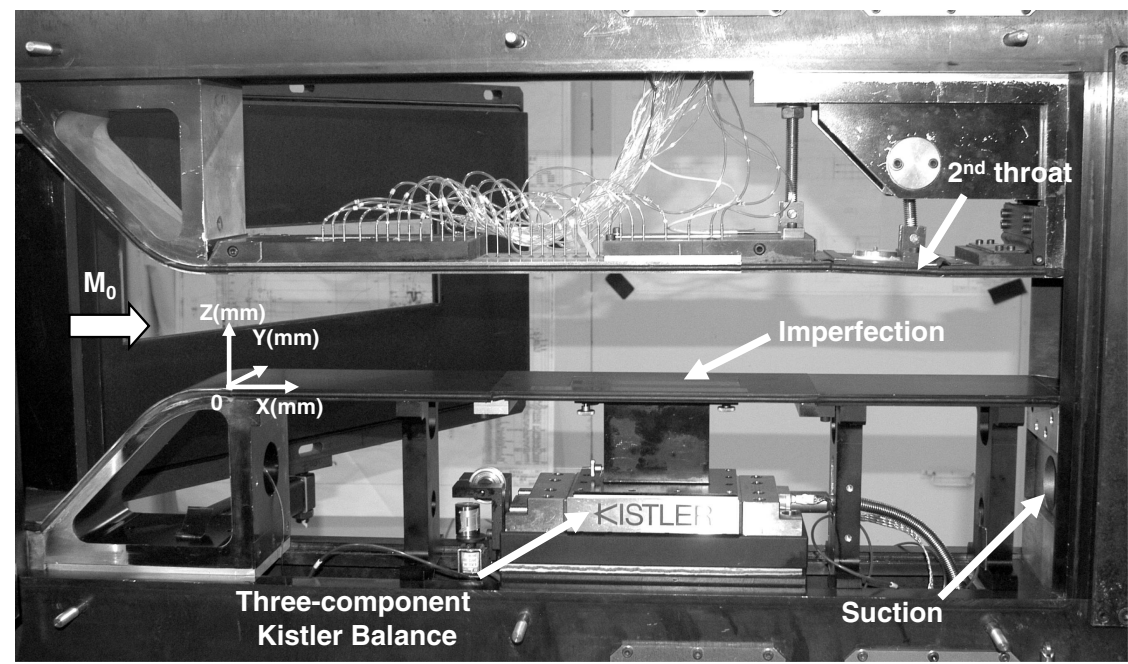

Fig. 1 Experimental setup in the $\mathrm{S8Ch}$ wind tunnel.

Stagnation conditions $\left(P_{i}, T_{i}\right)$ are close to the atmospheric pressure and room temperature. The flow in the tunnel is provided by a group of suction pumps with discharge in the atmosphere. The test section is $120 \mathrm{~mm}$ large and $100 \mathrm{~mm}$ high for a length of $500 \mathrm{~mm}$. The experimental setup is shown in Figs. 1 and 2. The origin of the $X$ axis corresponds to the input of the wind tunnel. The setup consists of a great flat plate $(120 \mathrm{~mm}$ large $)$, which starts at $X=230 \mathrm{~mm}$ and accommodates in its center a smaller plate, starting at $X=295 \mathrm{~mm}$ and being $150 \mathrm{~mm}$ long and $60 \mathrm{~mm}$ large. The great flat plate exhibiting a $150 \times 60 \mathrm{~mm}$ hole is unique, but each surface imperfection is machined on a different small plate, with the latter being then inserted into the great plate. The imperfection itself is located at $X=370 \mathrm{~mm}$ (i.e., the middle of the smaller plate). Its width is also of $60 \mathrm{~mm}$. As a consequence, the boundary layers of the wind-tunnel lateral walls are not supposed to interfere with the measurements focused on the small plate containing the imperfection. As it can be observed, the smaller plate is directly connected to the three-component balance, with a minuscule surrounding gap $(0.4 \mathrm{~mm})$ to ensure no contact disturbance during measurements. Moreover, it must be noticed that vertical coordinates at both ends of the small plate are the same (inclined ramps compensate the imperfection heights). Indeed, there should be no steps between the small plate and the great one. Furthermore, to maintain the equality between the pressures of the upper and lower cavities and therefore avoid unwanted vertical stresses, a suction pump is used (the hole is visible on the right side of the lower cavity).

The experiments were performed at three Mach numbers: in subsonic $\left(M_{0}=0.5\right)$, transonic $\left(M_{0}=0.8\right)$, and supersonic $\left(M_{0}=\right.$
1.3) regimes. The upper wall of the test section is equipped with 32 pressure taps so that the Mach number can be checked. For the tests in subsonic and transonic conditions, the throat located downstream allows adjusting the Mach number. For the supersonic conditions, a nozzle located close to the input of the wind tunnel is added (Fig. 2).

The imperfections considered in this paper (see Fig. 3) are forward-facing and backward-facing plain and chamfered steps. A more-specific imperfection shape is also presented. Seven configurations were studied for the backward-facing type (types 1 to 7) and four for the forward-facing one (types 8 to 11). The imperfection 12 is a combination of backward and forward-facing steps $(2$ and $1 \mathrm{~mm}$, respectively). All these imperfections are to be compared with the classical flat plate (type 0). The geometrical parameters are the heights (from 0.5 to $2 \mathrm{~mm}$ ) and angles of the steps $(15,45$, and $90 \mathrm{deg}$ ). Given the ratio between the heights of the imperfections and their width $(60 \mathrm{~mm})$, no three-dimensional (3-D) effects are expected.

The experimental boundary-layer thickness $\delta$ at the step location exhibits an order of magnitude of $10 \mathrm{~mm}$ (its exact value depending on the wind-tunnel conditions: $M_{0}, R e$, imperfection type). Given the heights of the steps considered here, the ratio $h / \delta$ varies from approximately 5 to $30 \%$ in this paper.

\section{B. Measurement Techniques: Description and Operational Qualification}

In this study, three types of techniques have been employed: measurements of stresses (drag force) with a three-component balance, measurements of velocity profiles around the surface

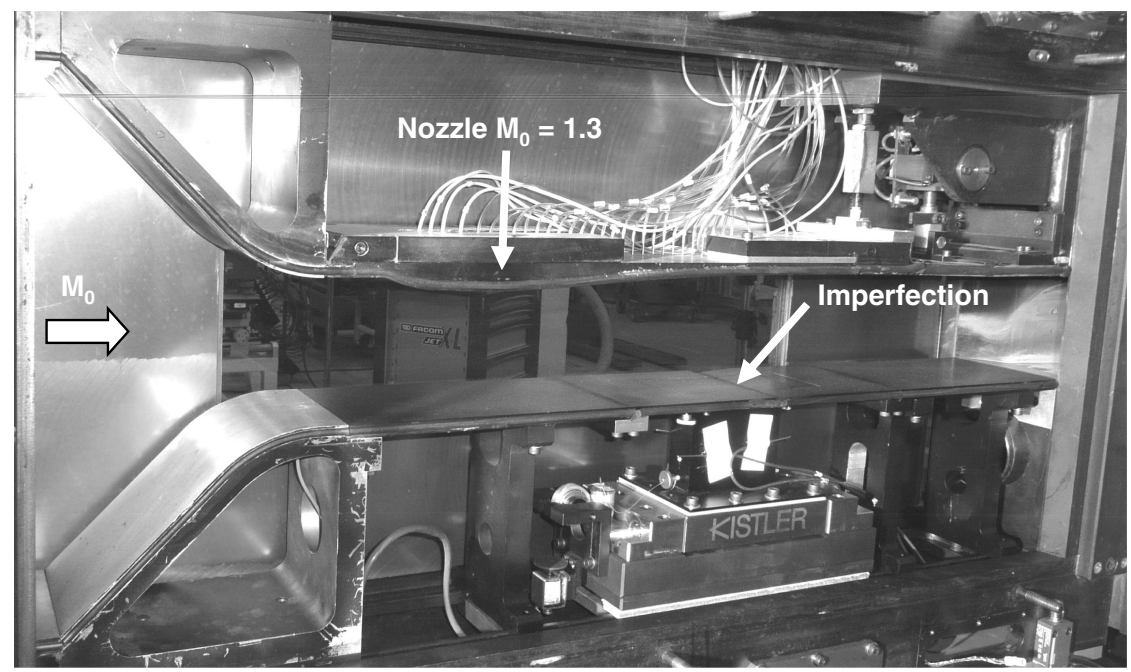

Fig. 2 Experimental setup in the $\mathrm{S8Ch}$ wind tunnel for the supersonic conditions. 


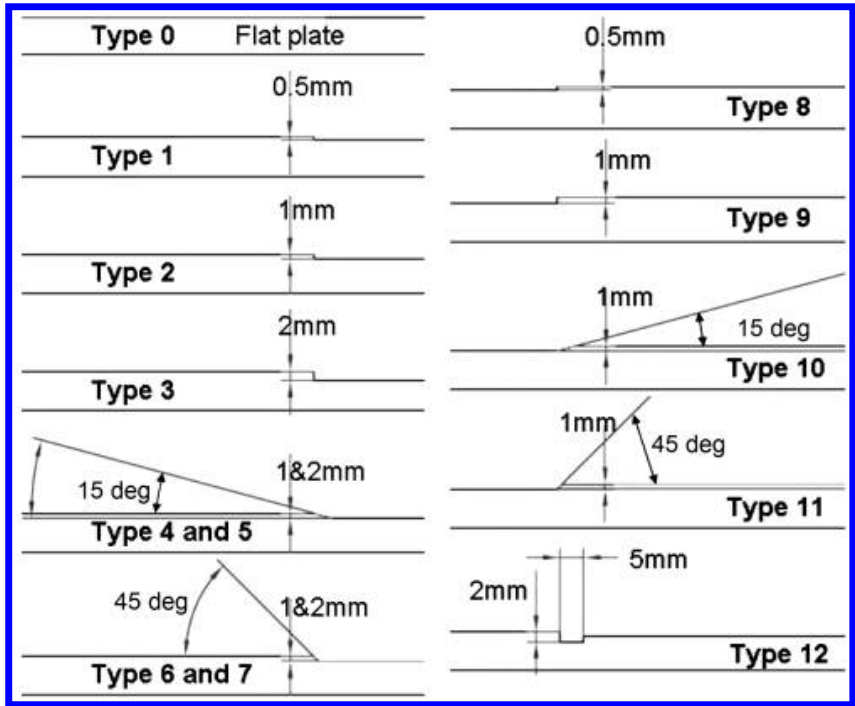

Fig. 3 Geometries of the surface imperfections.

imperfections with a two-component laser Doppler velocimetry system (LDV 2C), and measurements of skin frictions with an oilfilm interferometry method.

First, evaluations of the microdrag forces have been made using a dynamometric balance (Kistler), which allows absolute measurements of the stresses along the THREE axes with a high accuracy of $1 \mathrm{~g}$. An example of signal acquisition from the balance is shown in Fig. 4. The determination of the longitudinal stress applied by the flow on the small plate containing an imperfection has been done between states with and without flow (phases 2 and 4, respectively). The signal of each phase has been averaged on a period of $3 \mathrm{~s}$. Consequently, the drag force corresponds to the difference between the averages of phases 2 and 4 . It can be noticed that a reference mass has been used (phases 1 and 5) to ensure that no perturbations occurred during the acquisition cycle (such as contacts between small and great plates or setup deformations due to the wind-tunnel pump launch). For each drag measurement, the acquisition cycle has been performed 15 times. This has allowed calculating the average of the force and the standard deviation $( \pm 2.5 \%)$.

Then, the two-component LDV measurements have been performed [8]. The system exhibits a specific mechanical configuration with a short focal, which allows accessing measurement points very close to the wall [9]. The optical setup is used in "forward scattering" mode. The emission side consists of a laser Spectra Physics 2060 and a fiber beam splitter. The intersection of the two beam couples (blue and green) generates a $300 \times 80 \mu \mathrm{m}$ measurement area (see Fig. 5). The latter is constituted of two networks of

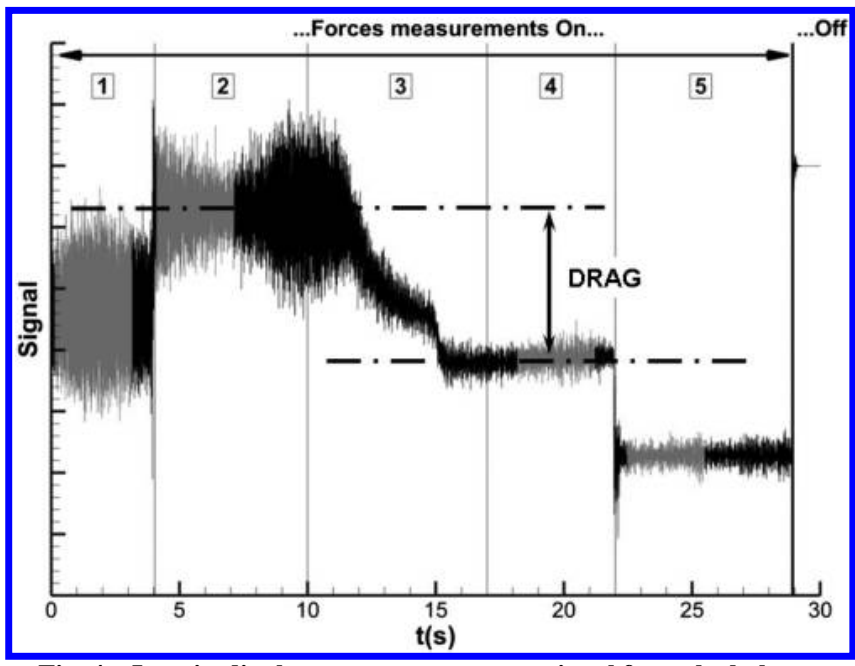

Fig. 4 Longitudinal stress measurements: signal from the balance.

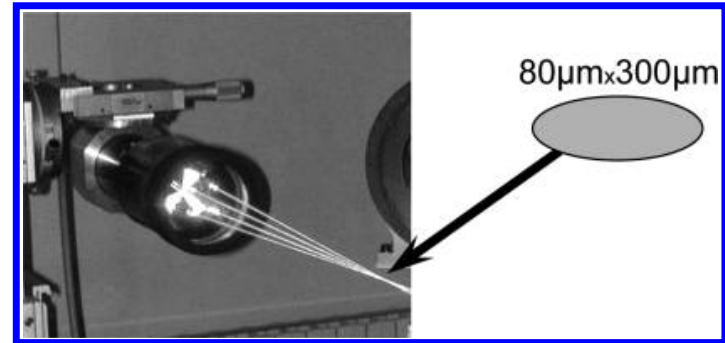

Fig. 5 LDV 2C: four laser beams constituting the measurement area.

interference fringes. On the other hand, the optical receiver is based on Cassegrain telescopes collecting the light flux from each particle. The signal acquisition is carried out by means of a TSI-IFA 755 system. The coincidence window is set to $1 \mu \mathrm{s}$. Raw recorded measurements are analyzed using the in-house code ASSA [10]. Besides, the flow is seeded with a generator located in the collector of the wind tunnel. The average size of the droplets is about $1 \mu \mathrm{m}$. In this study, the mean and fluctuating velocity components have been calculated by averaging over 20,000 particles for each measurement point (see Fig. 6). With this method, the velocity profiles have been extracted upstream the surface imperfections, to describe the flow conditions, and downstream, to characterize the boundary-layer detachment and/or reattachment.

Finally, the oil-film interferometry method [11-13] that has been used is a technique that allows determining the skin friction coefficient on a wall in the presence of an established turbulent boundary layer. Experimentally, a drop of oil is used to observe a small area where friction can be considered as constant. Under the flow action, the oil drop stretches and thins to form a film. During the measurements, white light is emitted. It is reflected by the test section wall but also by the upper surface of the oil film, which creates a network of interference fringes (see Fig. 7). The measurement area that has been watched by a camera was a $\overline{9} \times 13 \mathrm{~mm}$ rectangle. Recordings have been made using a Sony video camera of $2448 \times 2048$ pixels equipped with a $200 \mathrm{~mm}$ Nikon lens; the acquisition frequency has been set at $1 \mathrm{~Hz}$. A reference test pattern has been defined to determine the tilt angle of the camera relative to the vertical axis. This was necessary to readjust the pictures and to obtain the metric images (pixel number to distance conversion) $[14,15]$. Data evaluation has been performed on a restricted surface (see Fig. 8) by means of a code developed at ONERA [16]. One of the features of this method is the fact that the width of the fringes is directly related to the thickness of the oil film. The recording of the evolution over time of the fringe width (see Fig. 9), and therefore of the oil-film thickness, allows determining the local friction component. A previous ONERA study $[17]$, based on $[18,19]$, has shown that the uncertainty when applying an oil-film interferometry technique is mainly due to the measurement of the flow temperature, which has a key role on the oil viscosity. In the present test campaign, for each $X$ station, the oil-drop measurement has been done four times to confirm that the friction evaluation accuracy was satisfactory.

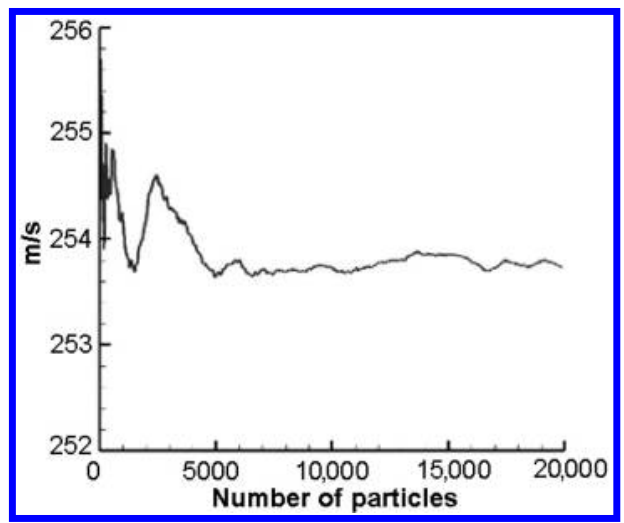

Fig. 6 LDV 2C: statistical convergence of the velocity $U$ (in meters per second). 


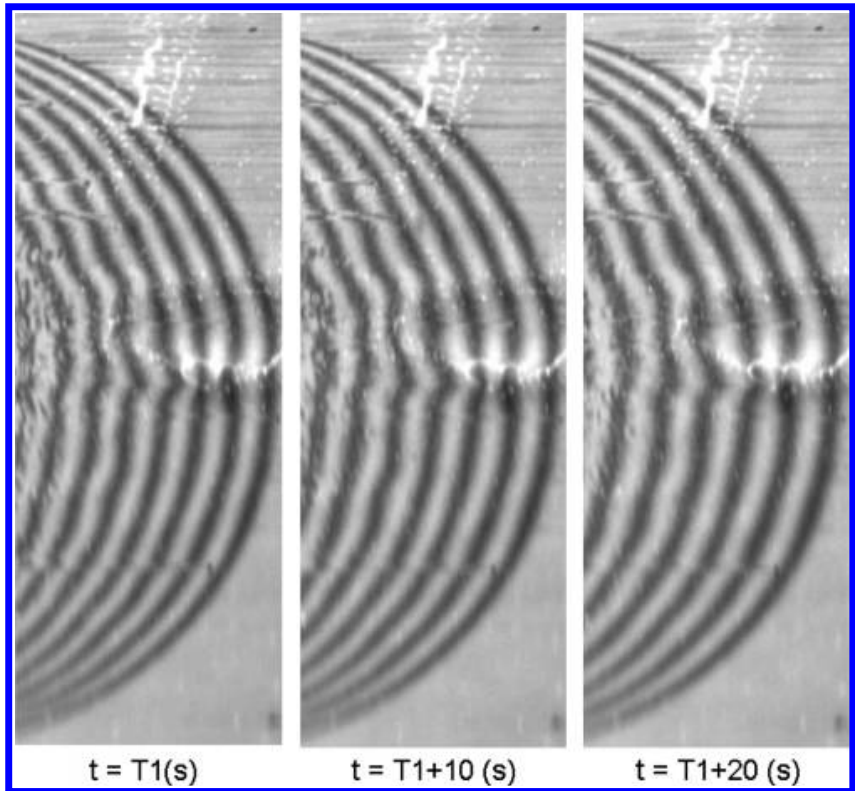

Fig. 7 Oil-film interferometry: spreading of oil drop.

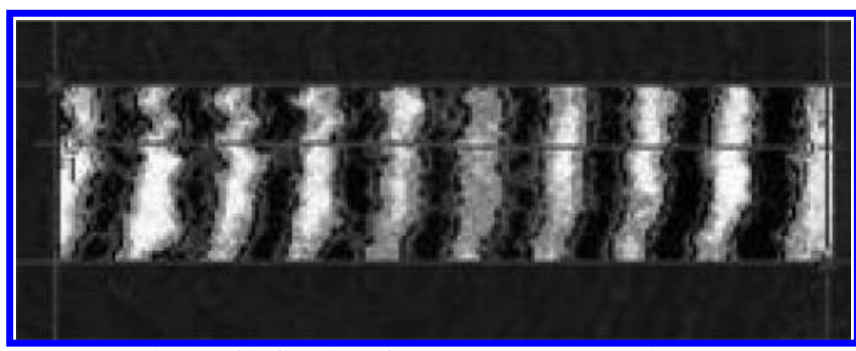

Fig. 8 Oil-film interferometry: data analysis area.

The first part of the test campaign focused on the operational qualification of the last two measurements techniques on a basic flat plate (type 0). First, the LDV 2C measurements have been assessed. This technique was aimed at being used for flow descriptions but also for skin friction evaluations via the Clauser approach [20]. It is this last point that is detailed next. The iterative method of Clauser consists of matching the logarithmic part of the boundary layer [see Eq. (1)] with the experimental profile by means of two parameters, which are the skin friction coefficient $C_{f}$ and the initial distance $Z_{1}$ between the wall and the first measurement point. For instance, for the reference flat plate at $M_{0}=0.8$ and $X=350 \mathrm{~mm}$, the first valid point appears at $Z^{+}<100$ (see Fig. 10):

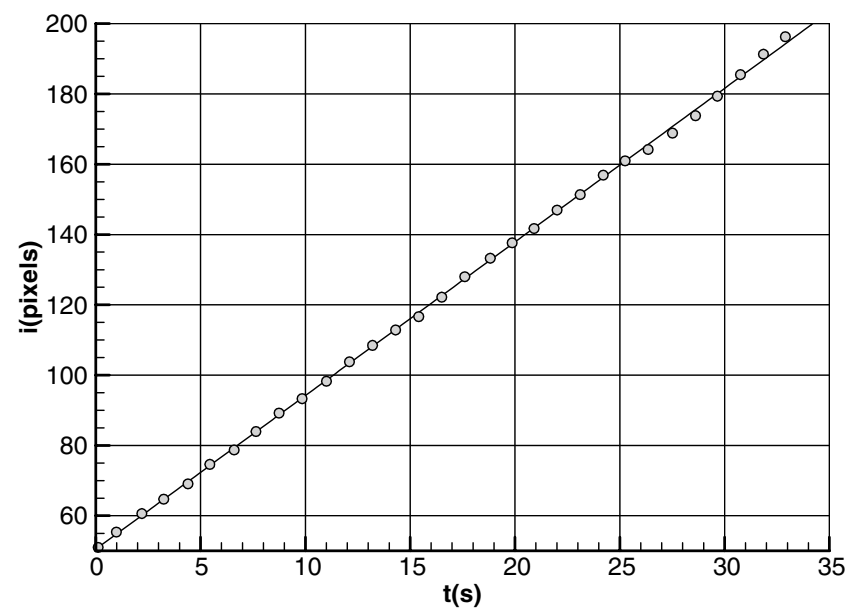

Fig. 9 Oil-film interferometry: fringe width vs time.

$$
U^{+}=\frac{1}{\chi} \ln \left(Z^{+}\right)+C
$$

with

$$
\begin{aligned}
Z^{+} & =\frac{Z \cdot U_{\tau}}{\nu}, \quad U^{+}=\frac{U}{U_{\tau}}, \quad U_{\tau}=U_{\infty} \sqrt{\frac{C_{f}}{2}}, \\
\chi & =0.41, \quad C=5
\end{aligned}
$$

This method is implemented in an in-house code that allows evaluating the skin friction coefficient at a given station where LDV measurements have been performed.

Still on the small flat plate (no imperfection), using this LDV $2 \mathrm{C}-$ Clauser approach, $C_{f}$ evaluations have been completed at different $X$ stations and Mach numbers. Results are shown in Fig. 11. In this figure, the experimental values are compared to the classical evolution of the friction coefficient in turbulent boundary layers [21], whose expression is given by the following equation:

$$
C f=\frac{0.0368 \cdot f}{R e^{1 / 6}}
$$

The compressibility factor $f$ in Eq. (2) takes into account the flow temperature, density, and viscosity. In Fig. 11, the reference evolutions are represented by lines. Experimental data are represented by symbols. For the first Mach number $M_{0}=0.5$, the trend of the experimental curve is satisfactory, but the points are below the corresponding line $(-2.5 \%$ at the imperfection location: $X=$ $370 \mathrm{~mm}$ ). For $M_{0}=0.8$, experimental results respect the correct trend, but the friction level is a bit higher than the reference value at the imperfection location (almost $+2.5 \%$ ). Finally, for the supersonic flow, the evolution is almost straight, and the level is lower than expected (about $-4 \%$ at the imperfection location). Given these figures, the skin friction evaluations obtained by the LDV $2 \mathrm{C}-$ Clauser method can be considered as quite satisfactory.

Then, to continue the qualification process, the oil-film interferometry technique has been applied on the reference flat plate at $M_{0}=0.8$. The skin friction values obtained with this method have been compared to these from the LDV $2 \mathrm{C}$ measurements. In Fig. 12, a good agreement is observed. Thus, downstream of the flow separations due to the different surface imperfections, where the Clauser method could be no longer valid, evaluations of the skin friction are still possible with the oil-drop technique.

\section{Numerical Procedure: Mesh Generation and Solver}

\section{A. Structured Grid Generation}

To carry out RANS computations aimed at being compared to the experimental measurements described previously, structured meshes have been realized for all the different geometries. This work has been completed with commercially available meshing software. The CFD General Notation System has been used.

The third dimension is not considered in this CFD study; the RANS meshes are consequently 2-D grids. The computational domain covers all the flat plate surrounding the considered small plat containing the imperfection, but the whole wind tunnel is not calculated. Therefore, the CFD domain starts at $X=230 \mathrm{~mm}$. Its length is $280 \mathrm{~mm}$, and its height $100 \mathrm{~mm}$ (Figs. 13 and 14). As mentioned previously, the small plate starting at $\bar{X}=295 \overline{\mathrm{mm}}$ is $150 \mathrm{~mm}$ long, and the step is located in its center. A global H-grid topology has been adopted, with each imperfection having its particular blocking. Point distributions have been chosen according to the experience of the Applied Aerodynamics Department of ONERA in this field. The boundary-layer area presents a very satisfactory grid density with a $y+$ close to 1 and a small vertical growth ratio of 1.1. The imperfection zone is particularly refined so that the flow phenomena close to the step are relatively well captured. The plates are defined as viscous walls; the upper and lateral surfaces are defined 


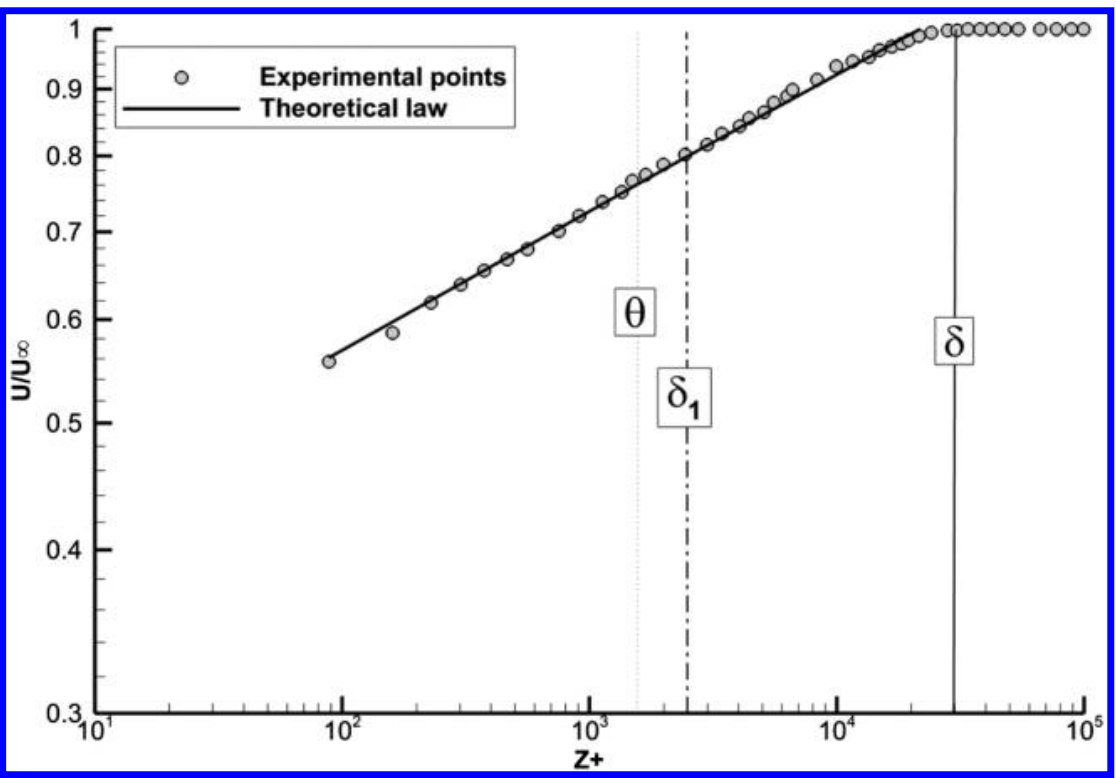

Fig. 10 Illustration of the Clauser approach: flat plate at $M_{0}=0.8$ and $X=350 \mathrm{~mm}$.

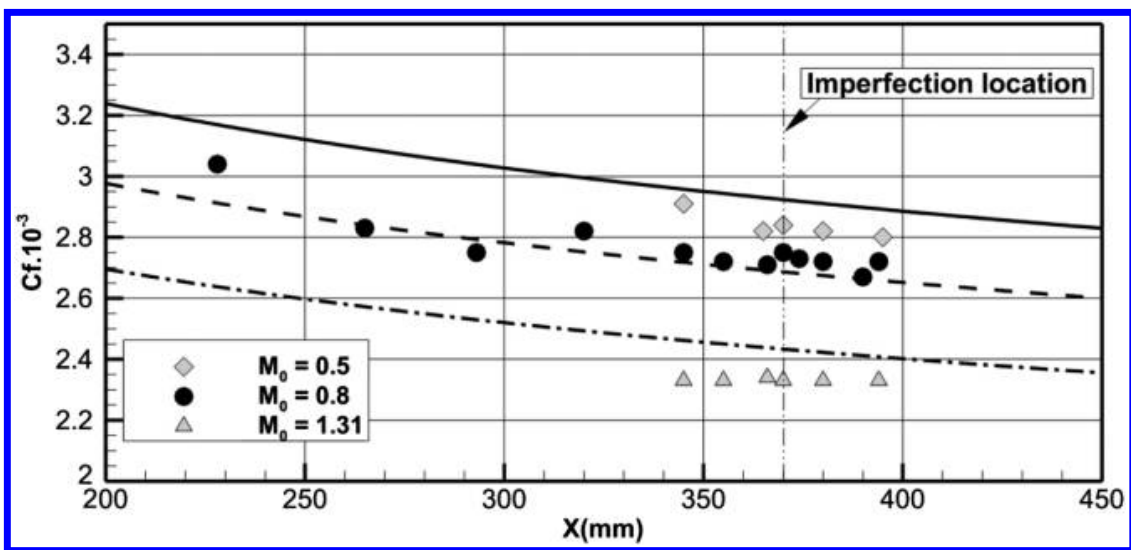

Fig. 11 Skin friction coefficients by the LDV 2C-Clauser method: flat plate at $M_{0}=0.5,0.8$, and 1.3 .

as far-field conditions (the wind-tunnel effects are therefore not taken into account); and the upstream and downstream frontiers are, respectively, inflow and outflow conditions. The order of magnitude for the size of these grids is about 50,000 points.

\section{B. ONERA elsA Solver}

Structured RANS computations have been performed with the ONERA elsA Navier-Stokes solver [22,23]. This software uses a cellcentered finite-volume discretization on structured and hybrid meshes.
Time integration is carried out by a backward-Euler scheme with implicit Lower Upper Symmetric Successive Overrelaxation (LUSSOR) relaxation. Spatial discretization is realized using a secondorder accuracy central Jameson scheme with artificial viscosity [24]. Multigrid techniques are used to accelerate the convergence.

All the computations have been performed in fully turbulent conditions. Turbulence effects have been simulated by the oneequation Spalart-Allmaras model [25] or the two-equation $k-\omega$ shear-stress transport (SST) model [26]. Particular attention has been

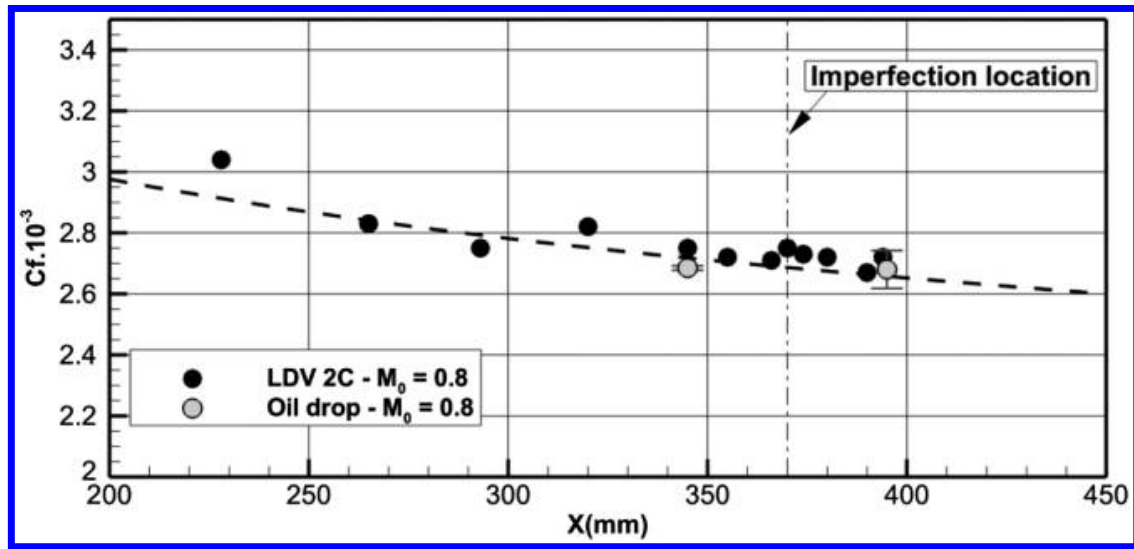

Fig. 12 Skin friction coefficients by the LDV 2C-Clauser and oil-film methods: flat plate at $M_{0}=0.8$. 


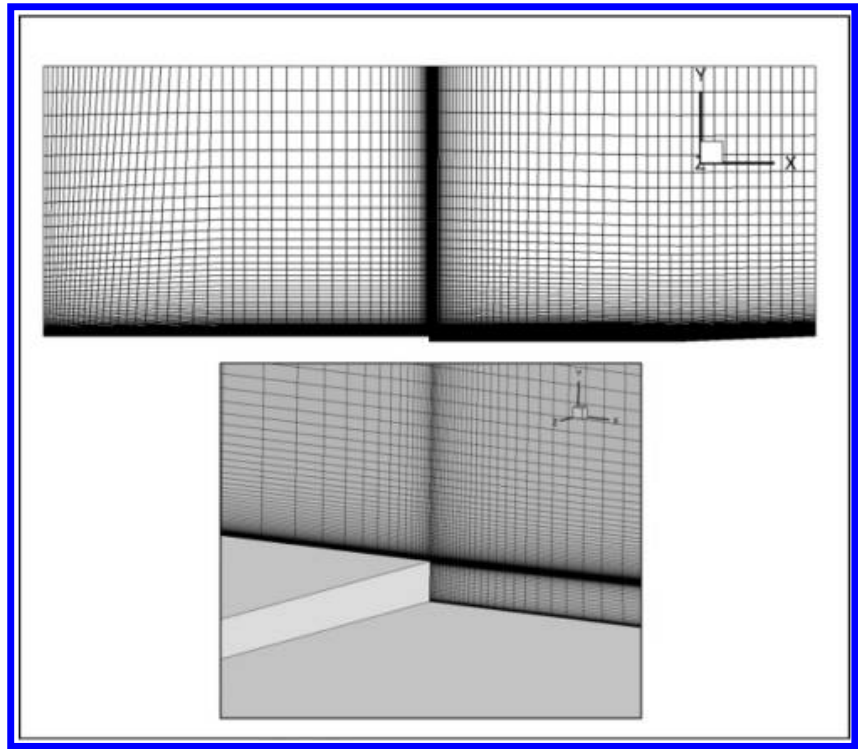

Fig. 13 Structured grid of the imperfection type 3.

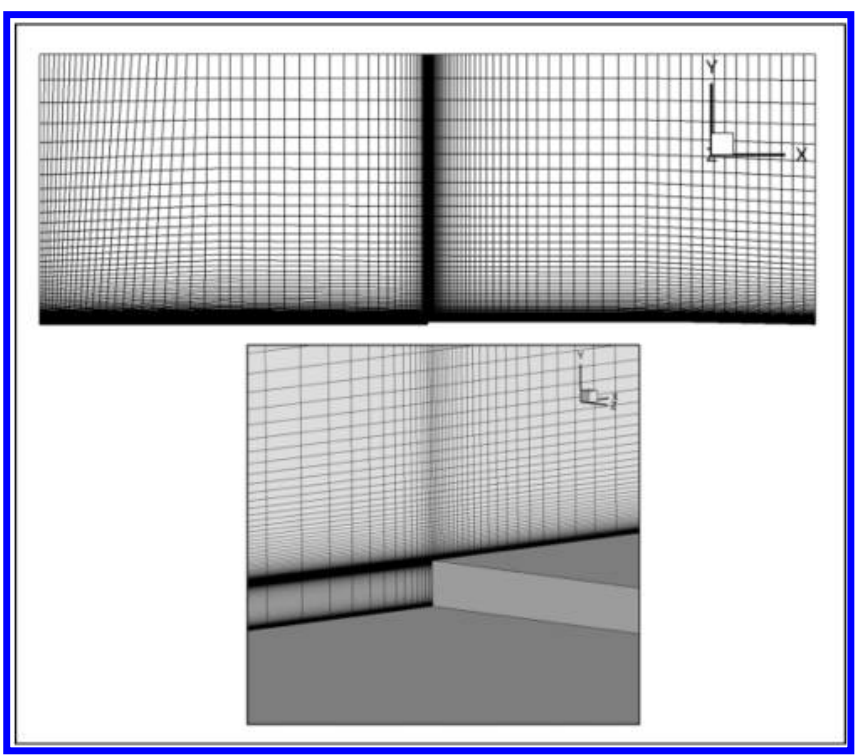

Fig. 14 Structured grid of the imperfection type 9. given to the gradient computation and surface extrapolation; these parameters are of prime importance for the evaluation of the friction drag.

The 2-D computations are realized in wind-tunnel aerodynamic conditions $\left(M_{0}, P_{i}, T_{i}\right)$. To reach a satisfactory level of convergence, the computations were continued until the fluxes were stable enough to observe a drag variation inferior to one drag count over the last thousand iterations (one drag count is $10^{-4}$ ). More than 10,000 iterations have been performed for each calculation. The elsA simulations were executed on a Silicon Graphics cluster (SGI ICE 8200) composed of 4992 cores.

As will be used in the paper, the classical breakdown of the nearfield drag is given here:

$$
C D=C D_{p}+C D_{f}
$$

$C D_{p}$ is the pressure drag and $C D_{f}$ is the friction drag. This breakdown is directly obtained with the CFD procedure.

\section{Results}

As mentioned previously, this study focused on three different Mach numbers in subsonic $\left(M_{0}=0.5\right)$, transonic $\left(M_{0}=0.8\right)$, and supersonic $\left(M_{0}=1.3\right)$ conditions. Experimental and numerical results are presented together so that they can be easily compared and commented. Only the imperfections for which both wind-tunnel and CFD evaluations were available are presented. Global results and local analyses are given. In figures showing the stresses, the longitudinal forces measured and computed for the flat plate (type 0 ) are respectively subtracted to the experimental and CFD values obtained for all the geometries. Thanks to this layout, the additional costs due to the imperfections are highlighted. For confidentiality reasons, the scales are not indicated.

\section{A. Subsonic Conditions: Mach 0.5}

The numerical aerodynamic conditions have been specified to be almost identical to the wind-tunnel ones. For the subsonic regime, they are the following: $M_{0}=0.5$, stagnation pressure $P_{i}=$ 0.97 Patm, stagnation temperature $T_{i}=300 \mathrm{~K}$, and Reynolds number of 2.7 million.

Figure 15 presents all the global experimental and CFD results obtained in subsonic conditions. The imperfection drag productions $(1,2,3,4,6,7,8,9,10,11$, and 12) are compared to the flat-plate production $(0)$.

Considering the wind-tunnel results, because the surface imperfections are very small, the associated stresses to be measured exhibit very low levels (possibly less than 0.1 Newton). Consequently, as said previously, the stress measurement for each imperfection has

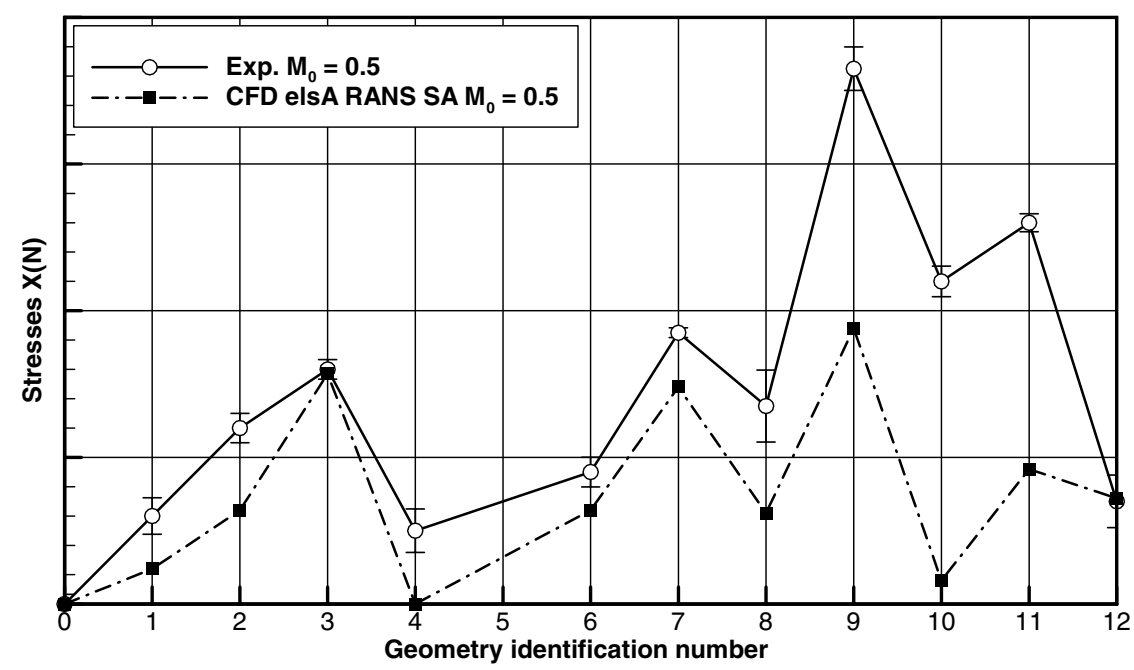

Fig. 15 Experimental/CFD relative comparison at $M_{0}=0.5$. 
been performed 15 times to evaluate the force average (symbols) and the measurement uncertainty (error bars). As it can be noticed in Fig. 15, the uncertainty depends on the imperfection; nevertheless, it can be said that, for the most-limited error bars, the order of magnitude of the measurement accuracy is close to the gram.

Concerning the numerical aspects, uniform velocity profiles have been used here for the inflow boundary condition. Indeed, given the very small order of magnitude of the stresses to be measured, this study has only focused on relative comparisons. For this purpose, uniform entrance profiles have been considered as satisfactory. For subsonic conditions, only the Spalart-Allmaras turbulence model has been used.

Considering Fig. 15, it can be observed that the experimental and numerical approaches give similar trends. Nevertheless, discrepancies exist. First, the agreement between stress measurements and calculations is much better for backward-facing steps (types 1 to 7 ) than for forward-facing ones (types 8 to 11).

Considering the imperfections 1 and 2, the relative positioning is the same for experimental and CFD evaluations: the $1 \mathrm{~mm}$ plain backward-facing step drag production (2) is about twice stronger than the $0.5 \mathrm{~mm}$ one (1). Then, a very good agreement is observed for the $2 \mathrm{~mm}$ backward-facing step (3).

This is not the case for the imperfection 4 . The experiments predict that the 15 deg chamfered backward-facing step of $1 \mathrm{~mm}$ (4) is equivalent to a $0.5 \mathrm{~mm}$ plain backward-facing step (1) in terms of drag production. The RANS evaluation is different and shows a drag level close to the flat-plate production for the imperfection 4 ; it is explained by the existence of a small flow separation at the footstep, which makes the friction drag coefficient of this imperfection lower than the one of the flat plate. With this flow separation being very limited, the creation of pressure drag is low, and the sum of the two components corresponds to a force close to the flat-plate drag production.

The imperfections 6 and 7, which are 45 deg chamfered backwardfacing steps of 1 and $2 \mathrm{~mm}$, give experimental and numerical results that show quite satisfactory agreement, with the CFD stresses being a bit lower than the wind-tunnel ones.

To add another source of data to this discussion, the work of the Royal Aircraft Establishment (RAE) [27] is introduced here. In that paper of 1973, the drag-production measurements of steps very similar to the ones of the present study are given for several Mach numbers. The ratio $h / \delta$ of the British experiments is quite low (inferior to 3\%). Nevertheless, this reference is a good database for comparison purposes. For instance, considering the imperfections 2 and 6, the RAE paper indicates that, in subsonic conditions, the 45 deg chamfered backward-facing step (6) produces a drag level almost identical to the one of the plain step of same height (2). This result is particularly well reproduced by the CFD approach here.
Concerning now the forward-facing steps (types 8 to 11), it can be observed that the experimental tests give high drag levels compared to backward-facing steps and CFD predictions. Nevertheless, the calculations provide similar trends.

Concerning the imperfection 8 , a $0.5 \mathrm{~mm}$ plain forward-facing step, the absolute comparison between measurement (nonnegligible relative uncertainty) and calculation does not show a good agreement, but each method is consistent by indicating that the $0.5 \mathrm{~mm}$ plain forward-facing step (8) is approximately equivalent to a $1 \mathrm{~mm}$ plain backward-facing step (2) in terms of drag production.

For the imperfections 9,10, and 11, substantial differences appear between the measured and computed drag levels of each type. However, if only these imperfections are considered, it can be noticed that their relative positioning is similar for both approaches.

Gaudet and Winter [27] give measurements showing the relative positioning of the drag productions of these types of excrescences ( 9 to 11). According to this source, the $45 \mathrm{deg}$ chamfered forwardfacing step (11) is supposed to produce a drag representing only the half of the one generated by the plain forward-facing step (9). Concerning the $15 \mathrm{deg}$ chamfered forward-facing step (10), the British tests give a drag level of approximately $15 \%$ of the one of the plain step (9). As it can be observed in Fig. 15, CFD results are in good agreement with these figures.

Then, it can be observed that the relative positioning of the imperfections 8 and 10 is different between the wind-tunnel measurements (drag production of 10 stronger than the one of 8 ) and the CFD calculations (drag level of 10 lower than the one of 8). The RANS computation predicts no flow separation for the 15 deg chamfered forward-facing step (10) and almost no pressure drag production; therefore, the drag level computed is very low, smaller than the $0.5 \mathrm{~mm}$ backward-facing step (1). The experiments exhibit flow separations for this geometry.

As a last point, the particular imperfection 12 (see Fig. 3) exhibits here a very good agreement between experimental and numerical drag evaluations. The stress produced by this surface imperfection is quite close to the one computed for the $1 \mathrm{~mm}$ plain backward-facing step (2). As a consequence, even if this imperfection includes a $2 \mathrm{~mm}$ plain backward-facing step, its geometrical features make it equivalent to a $1 \mathrm{~mm}$ backward-facing step in term of drag production. This type of information is of prime interest for aircraft manufacturers. It can help choosing imperfection shapes that exhibit better aerodynamic performances. The reasons for this global result will be explained further by local flow analyses.

To conclude, experimental and numerical trends are similar. Relative positioning is respected for most of the imperfections. Nevertheless, the experimental drag measurements for forwardfacing steps show values much stronger than the numerical ones. To understand the global results commented previously, measurements

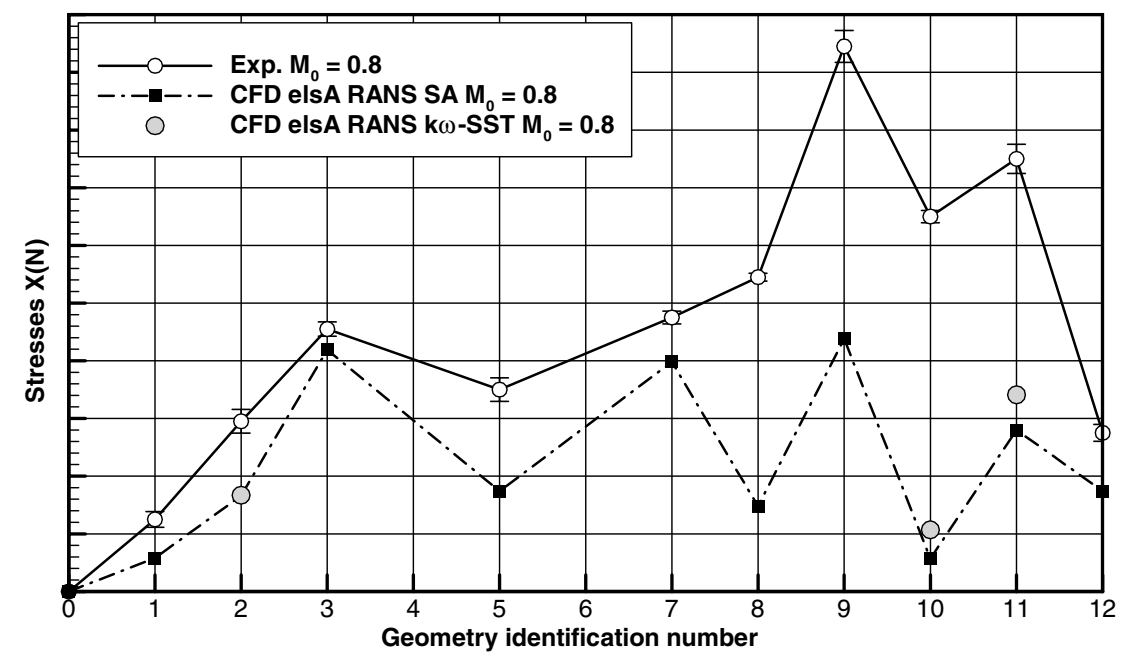

Fig. 16 Experimental/CFD relative comparison at $M_{0}=0.8$. 


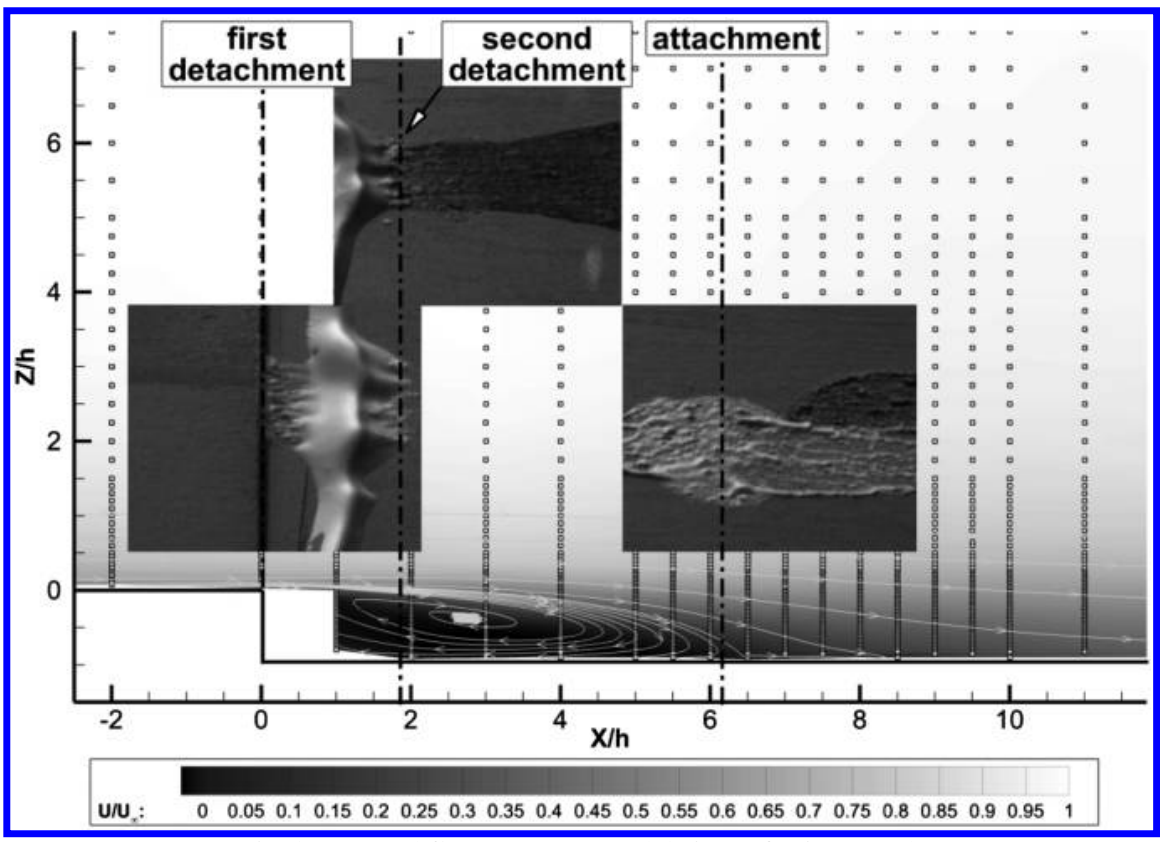

Fig. 17 LDV 2C results at $M_{0}=0.8$ : imperfection type 3 .

by LDV $2 \mathrm{C}$ and oil-film interferometry have been realized in transonic conditions. They are presented in the next section.

\section{B. Transonic Conditions: Mach 0.8}

The numerical aerodynamic conditions have been chosen to be very close to the wind-tunnel conditions. For the transonic regime, they are the following: $M_{0}=0.8, P_{i}=0.97$ Patm, $T_{i}=300 \mathrm{~K}$, and Reynolds number of 3.68 million.

Figure 16 presents the global experimental and CFD results obtained in transonic flow. The imperfections $(1,2,3,5,7,8,9,10$, 11 , and 12) are compared to the flat plate (0). For the reasons given in the previous paragraph, uniform velocity profiles have been used for the inflow boundary condition. The Spalart-Allmaras and Menter $k-\omega$ SST turbulence models have been evaluated. It can be observed that the measurement relative uncertainties (error bars) are globally more limited in transonic conditions than they were in the subsonic regime.

Considering Fig. 16, it can be observed that the general comments made for the subsonic case are still valid. The agreement between experimental and numerical sources is still better for backwardfacing steps (types 1 to 7). It can be noticed that the Menter $k-\omega$ SST turbulence model modifies the CFD results for the imperfections 10 and 11 (by increasing the drag production due to friction).

A point to be commented is the particular position of the windtunnel drag measurement for the imperfection 8 , which is the $0.5 \mathrm{~mm}$ plain forward-facing step. For the CFD approach, the behavior here is consistent with the one observed in subsonic conditions: the imperfection 8 produces a drag level close to the one of the $1 \mathrm{~mm}$ plain backward-facing step (2). On the contrary, the drag measurement shows a drag production for the step 8 even stronger than the one of the $2 \mathrm{~mm}$ plain backward-facing step (3), which is not in agreement with the experimental outcomes in subsonic conditions. This point has not been explained yet.

In transonic conditions, [27] also gives interesting results. For a Mach number of 0.8 , it indicates that a plain and a $45 \mathrm{deg}$ chamfered backward-facing steps of same height produce identical drag levels. It corresponds in this paragraph to the imperfections 3 and 7 . It can be noticed in Fig. 16 that these results of [27] are in good agreement with both methods of the present study. In [27], the 15 deg chamfered backward-facing step (5) at this Mach number generates a drag quite close to the one of the plain step (3). The S8Ch experiments seem to exhibit better agreement with [27] than the numerical method in this case. Focusing on the forward-facing steps, according to [27], a $45 \mathrm{deg}$ chamfered forward-facing step (11) leads to a drag production representing approximately $60 \%$ of the one generated by the plain forward-facing step of identical height (9). Moreover, the $15 \mathrm{deg}$ chamfered forward-facing step (10) generates a very low drag level of only 10 to $15 \%$ of the one of the plain step (9). These figures are reproduced quite accurately by the CFD study presented here.

The disagreement in CFD/experimental relative positioning of the imperfections 8 and 10 is also observed in transonic conditions.

Concerning the imperfection 12 (see Fig. 3), the agreement is still good between experimental and numerical evaluations. In transonic conditions also, the stress produced by this imperfection is quite close to the one of the $1 \mathrm{~mm}$ plain backward-facing step (2).

Then, as said previously, in addition to the stresses measurements and computations, local analyses have been carried out. These investigations focused on the evaluation of the skin friction coefficient at different stations and on the flow separation characteristics. The LDV and oil-film measurement techniques have been used. For these local comparisons, RANS computations have been completed with entrance velocity profiles directly interpolated from wind-tunnel data at the same station. For the flat plate at $M_{0}=0.8$, the experimental boundary-layer thickness $\delta$ at $X=295 \mathrm{~mm}$ (i.e., $75 \mathrm{~mm}$ before the imperfection location) is equal to about $9 \mathrm{~mm}$.

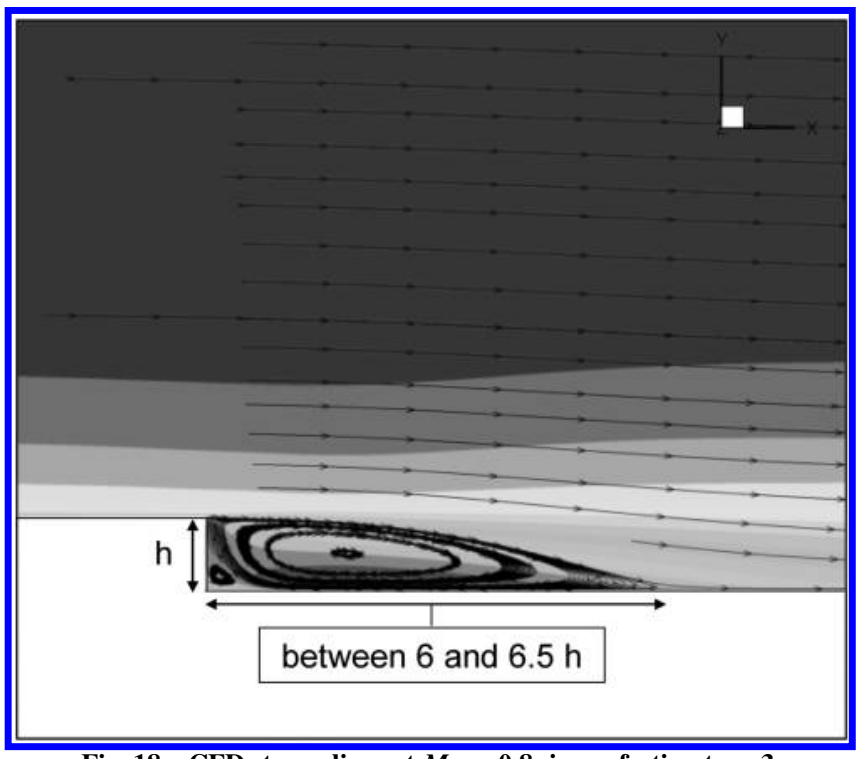

Fig. 18 CFD streamlines at $M_{0}=0.8$ : imperfection type 3 . 


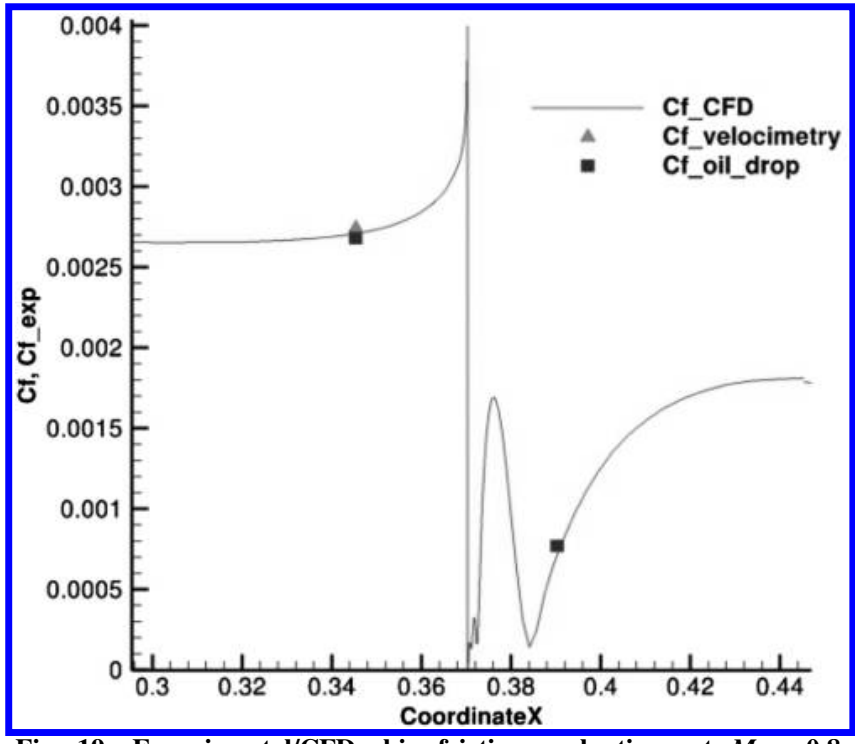

Fig. 19 Experimental/CFD skin friction evaluations at $M_{0}=0.8$ : imperfection type 3 .

Imperfections 3 and 9 have been selected for deeper analyses. The type 3, a $2 \mathrm{~mm}$ plain backward-facing step, is the imperfection showing the best experimental/CFD agreement in terms of drag production $(h / \delta \approx 20 \%)$. On the other hand, the imperfection 9 is one of the geometries that exhibit the greatest disagreements $(h / \delta \approx 10 \%)$. Because of its particular geometrical features, the imperfection 12 has also been deeply studied.

Focusing on the imperfection 3, typical results of the LDV 2C measurements are shown in Fig. 17. The white zone just downstream of the step corresponds to an area where LDV measurements have not been performed (mostly for difficulty reasons). Relevant oil flow visualizations are added (top views); they have been realized with single drops instead of oil films. Indeed, with the phenomena to be observed being very small, the use of a single drop allows better flow visualizations. However, with this method (side effects due to the oildrop size), the flowfield seems to be nonuniform in the spanwise direction (but it is uniform). Anyway, this visualization is useful to observe the flow separation features. As it can be seen in this figure, the main flow separation (first detachment) at the step trailing edge extends to more than $6 h$. The largest recirculation flow, characterized by a great vortex, generates another separation (second detachment) and a second vortex (not visible in the LDV 2C results). Downstream, the flow reattaches to the wall (attachment). The boundary-layer thickness at the step abscissa is about $8 \mathrm{~mm}$.

The equivalent result from CFD is exhibited in Fig. 18. With the streamlines, the elsA computation allows estimating the flow separation length; it is about 6 to $6.5 h$, which is in very good agreement with the LDV measurements. As it can be noticed, the second vortex is clearly visible at the footstep. The visual comparison of Figs. 17 and 18 is quite satisfactory.

Considering the skin friction coefficient evaluation, Fig. 19 also shows very good agreement between continuous CFD curve and experimental measurement points upstream and downstream of the backward-facing step 3. It can be seen that the LDV and oildrop measurements are in very good agreement upstream of the imperfection. Then, downstream of the step where the LDV-Clauser skin friction evaluation is not accurate anymore (as said previously), the oil-drop measurement gives a skin friction coefficient value in perfect agreement with the numerical one. Therefore, for this plain backward-facing step (3), the numerical and experimental local results are in very good agreement.

Focusing now on the imperfection 9, the $1 \mathrm{~mm}$ plain forwardfacing step, results of the LDV $2 \mathrm{C}$ measurements and oil flow visualizations are shown in Fig. 20. The flow separation length downstream of the step can be estimated as close to $3.5 h$. The flow separation extent upstream of the step is about $2 h$. Upstream and downstream of the step, the boundary-layer thickness is impacted by the flow separations.

The equivalent result from CFD is exhibited in Fig. 21. In this case, the reattachment point downstream of the step is located about $4 h$ after the imperfection, and the flow separation extent upstream of the step is estimated at about $2 h$, which is in good agreement with the measurements. The downstream flow separation extent is more than twice longer than the upstream separation one.

Concerning the skin friction coefficient evaluation, Fig. 22 shows the discrepancies between continuous CFD curve and experimental measurement points upstream and downstream of the forward-facing step 9. It can be noticed that the numerical levels of friction are lower than the wind-tunnel ones. This was expected because the same behavior has been observed with the stress evaluations. Once again, the numerical method seems to be consistent with the experimental one (equivalent friction levels exist on both sides of the imperfection for both approaches), but the experimental friction intensity is greater. Considering that the CFD results are in agreement with [27] for this excrescence type, an experimental effect affecting especially the forward-facing steps is not excluded. To conclude, for this plain

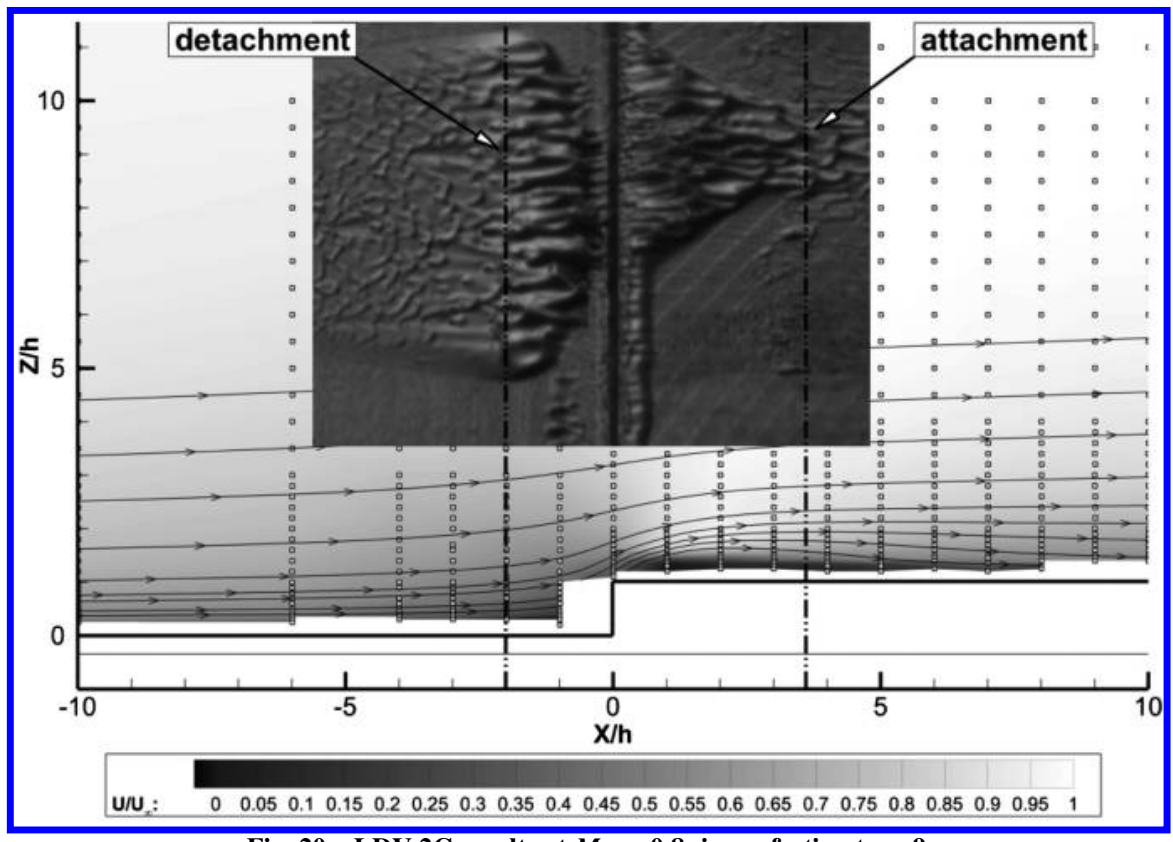

Fig. 20 LDV 2C results at $M_{0}=0.8$ : imperfection type 9. 


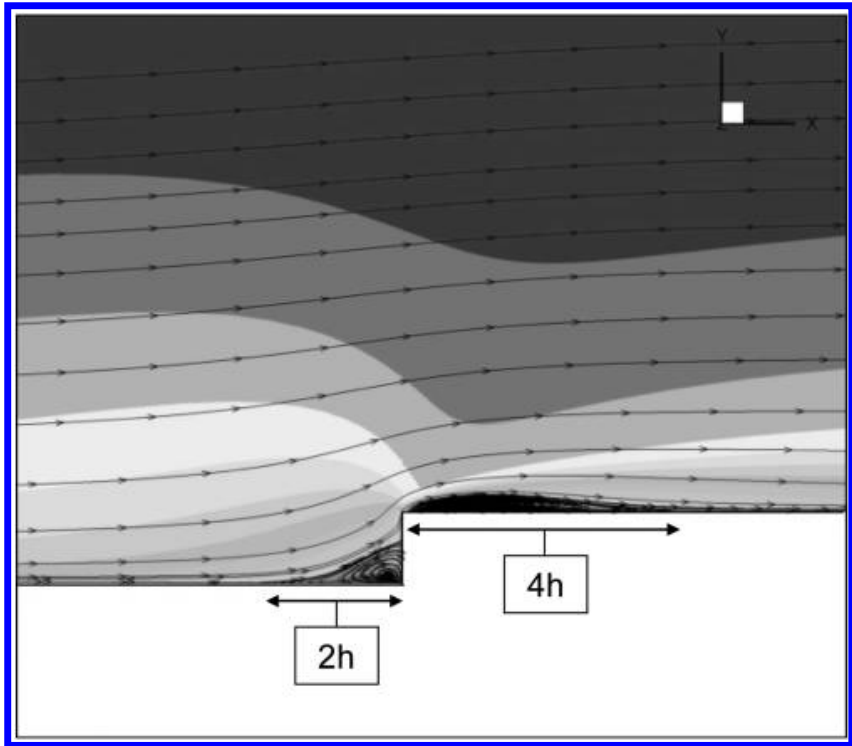

Fig. 21 CFD streamlines at $M_{0}=0.8$ : imperfection type 9.

forward-facing step (9), the numerical and experimental local results are not entirely in good agreement. Even if the flow separation extents seem to be well predicted by CFD, the skin friction evaluations show significant level discrepancies.

Concerning the imperfection 12 , this specific imperfection is the combination of a backward-facing step of $2 \mathrm{~mm}$ and a forward-facing step of $1 \mathrm{~mm}$. It has been shown that the stress produced by this surface imperfection is quite close to the one of the $1 \mathrm{~mm}$ plain backward-facing step (2). The reasons for this result can be explained by local analyses. Indeed, as shown the LDV $2 \mathrm{C}$ measurements in Fig. 23, the special features of this imperfection induce a confinement of the downstream flow separation. This flow behavior is confirmed by the CFD approach in Fig. 24. As it can be noticed, the flow topology is very similar to what is observed in Figs. 17 and 18 with the $2 \mathrm{~mm}$ plain backward-facing step (3). A second vortex is visible at the footstep in both cases. However, with the imperfection 12, the main flow separation extent is reduced to the physical distance between the backward-facing step and the forward-facing one (i.e., $2.5 h$, where $h$ is the height of the first step). This extent of $2.5 h$ is

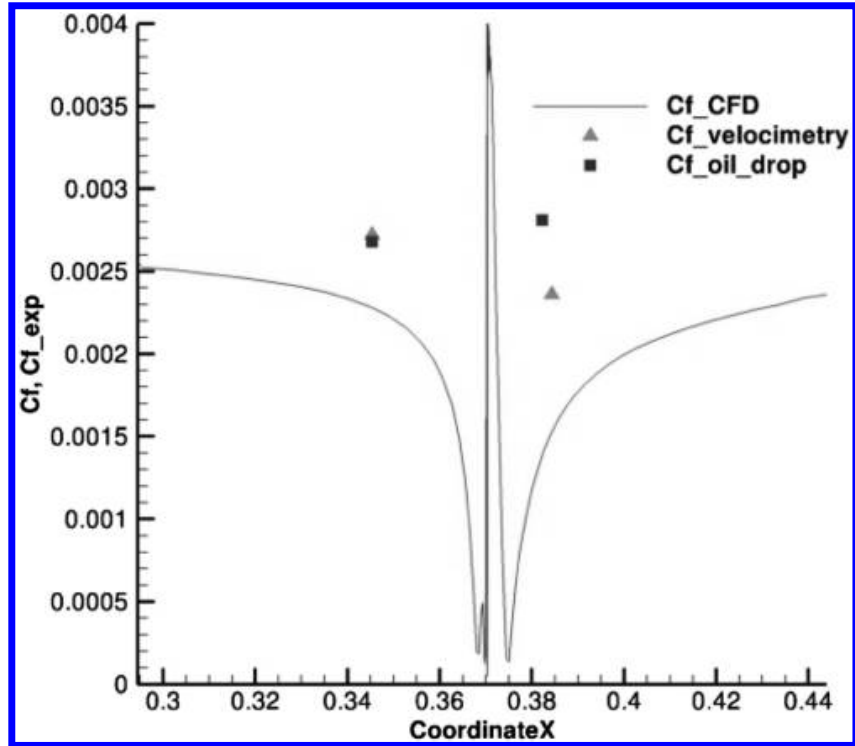

Fig. 22 Experimental/CFD skin friction evaluations at $M_{0}=0.8$ : imperfection type 9 .

more than halved compared to the flow separation extent of about $6 h$, which was observed with the imperfection 3 . This confinement of the flow separation explains why the drag produced by the imperfection 12 is close to the one of the backward-facing step of only $1 \mathrm{~mm}$.

Another interesting point of this study is the drag breakdown allowed by the CFD approach; the computed stresses can be expressed in pressure and friction drag components. Indeed, considering the classical flat plate (without step), the total drag is composed only of friction drag. For all the different step geometries that have been calculated, Fig. 25 shows the near-field drag coefficients in drag counts. It can be observed that it is mainly the pressure drag that determines the relative positioning of one imperfection in terms of total drag production. In these transonic conditions, the friction drag coefficient variation is very limited (with the imperfections producing the lowest $C D f$ being the ones exhibiting the greatest flow separations). On the other hand, the pressure drag variation when considering all the geometries is substantial. For several of them $(3,7,9)$, the pressure component is even stronger than the friction one.

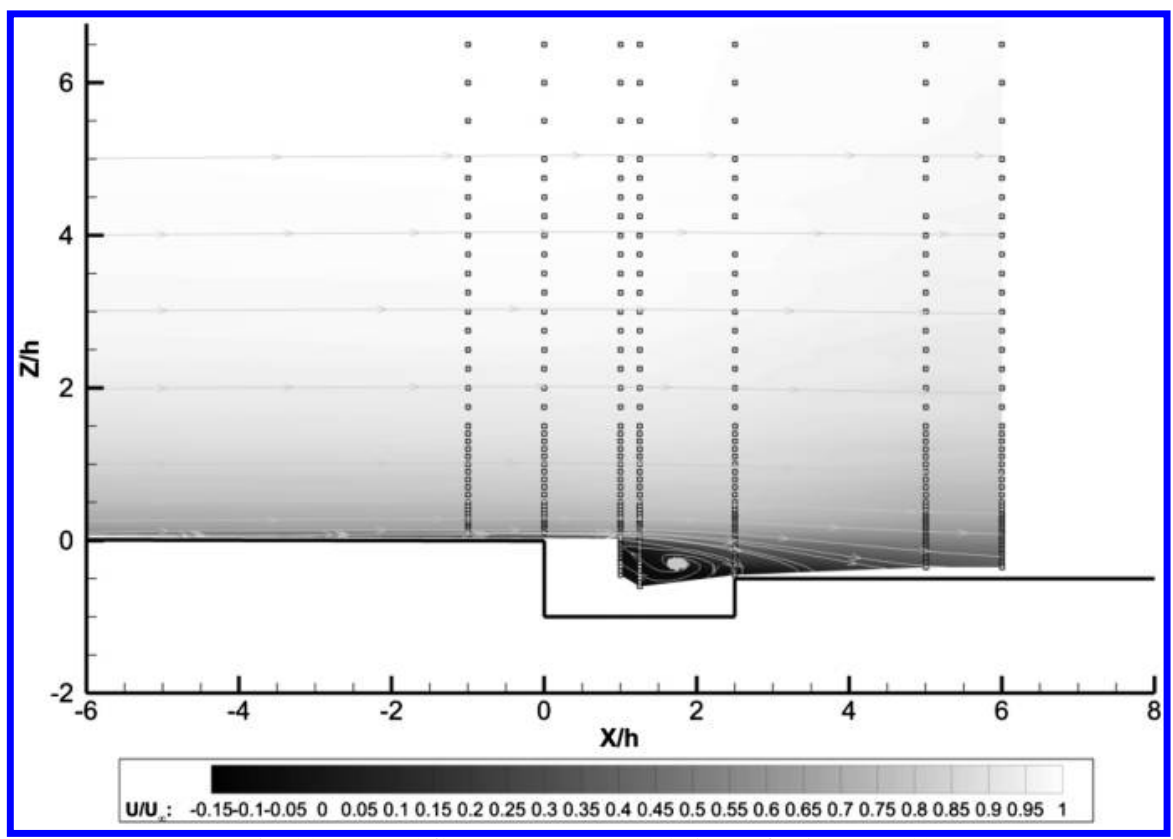

Fig. 23 LDV $2 \mathrm{C}$ results at $M_{0}=0.8$ : imperfection type 12 . 


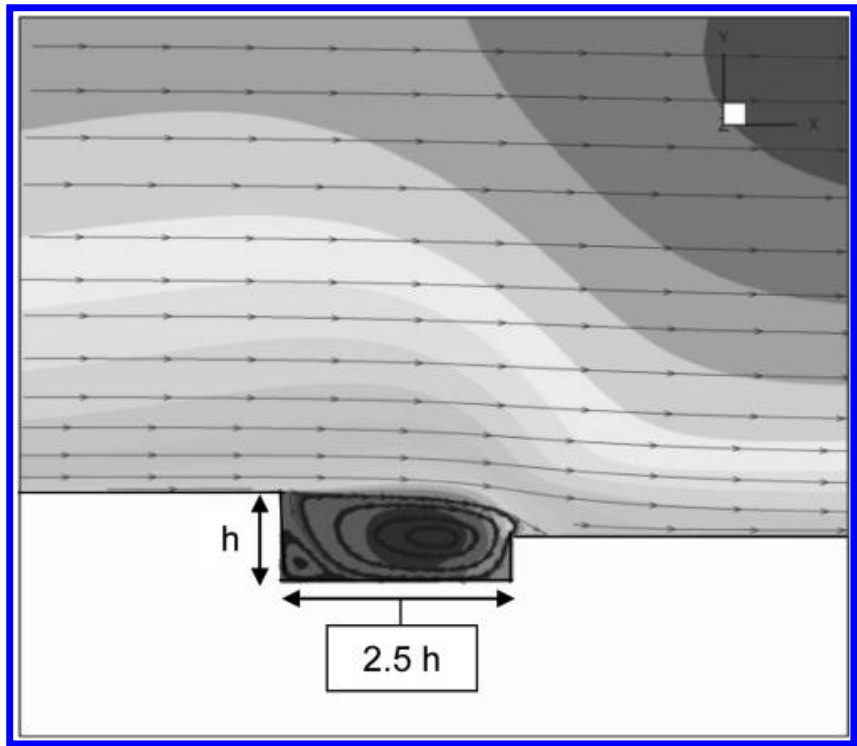

Fig. 24 CFD streamlines at $M_{0}=0.8$ : imperfection type 12 .

\section{Supersonic Conditions: Mach $\mathbf{1 . 3}$}

For the supersonic regime, the numerical and experimental aerodynamic conditions are the following: $M_{0}=1.3, P_{i}=0.97$ Patm, $T_{i}=300 \mathrm{~K}$, and Reynolds number of 4.1 million.

Figure 26 presents the global experimental and CFD results obtained in supersonic conditions. The imperfections $(1,2,3,4,6,8$,
9,10 , and 11) are compared to the flat-plate drag production (0). For the reasons given in the previous paragraphs, uniform velocity profiles have been used for the numerical inflow boundary condition. The Spalart-Allmaras and $k-\omega$ SST turbulence models have been employed.

Considering Fig. 26, it can be noticed that the experimental/ numerical comparison is particularly satisfactory at this regime. Contrary to the subsonic and transonic cases, this agreement is still good with forward-facing steps (types 8 to 11). Indeed, the forwardfacing steps do not produce drag levels here much larger than the backward-facing imperfections; it was not the case in the former paragraphs.

In supersonic conditions, for the flat plate, the experimental boundary-layer thickness $\delta$ at $X=295 \mathrm{~mm}$ is equal to about $6 \mathrm{~mm}$. It is thinner than it was for the transonic case. Comparing Figs. 20 and 27 (oil flow visualizations), it can be observed that the flow separations at $M_{0}=1.3$ are smaller than the ones at $M_{0}=0.8: 1.5 h$ versus $2 h$ for the upstream flow separation extents and only $1.9 h$ versus $3.5 h$ for the downstream ones. The fact that the downstream flow separation of forward-facing steps is particularly reduced in supersonic conditions partly explains why the drag production of an imperfection such as 9 is not much stronger than the one of the imperfection 2 (Fig. 26). The Menter $k-\omega$ SST and Spalart turbulence models almost give identical results.

A difference of positioning is observed between the imperfections 4 and 6; the experiments predict a greater drag production for the step 6 , whereas the CFD approach indicates the opposite. Nevertheless, the differences are not large enough to be very significant. Finally, contrary to the former cases, CFD and experiments agree on the relative positioning of imperfections 8 and 10 .

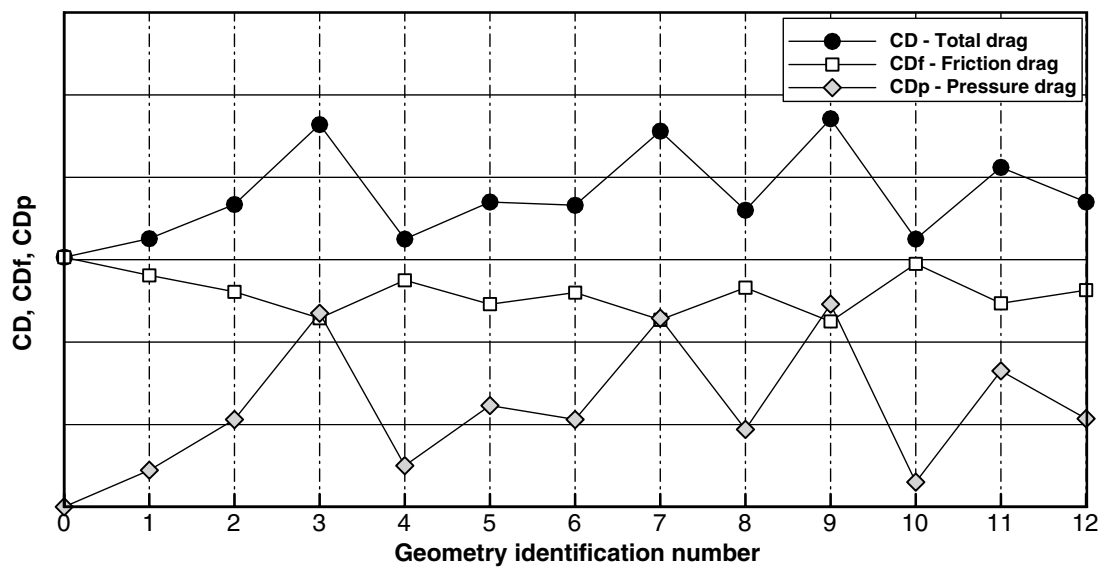

Fig. 25 CFD drag breakdown at $M_{0}=0.8$.

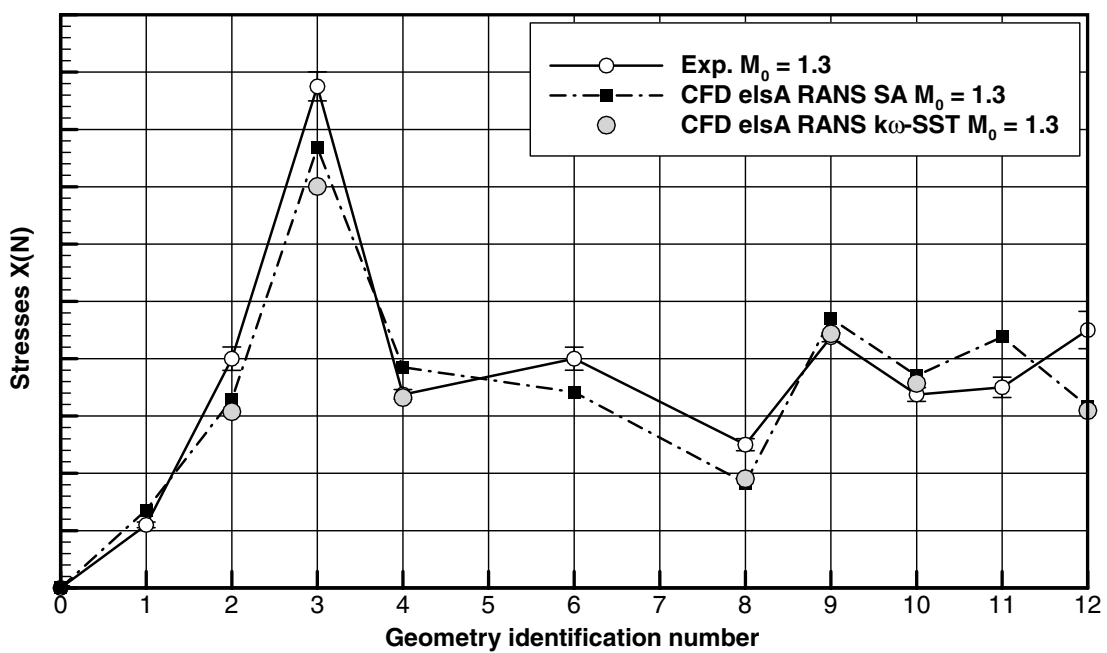

Fig. 26 Experimental/CFD relative comparison at $M_{0}=1.3$. 


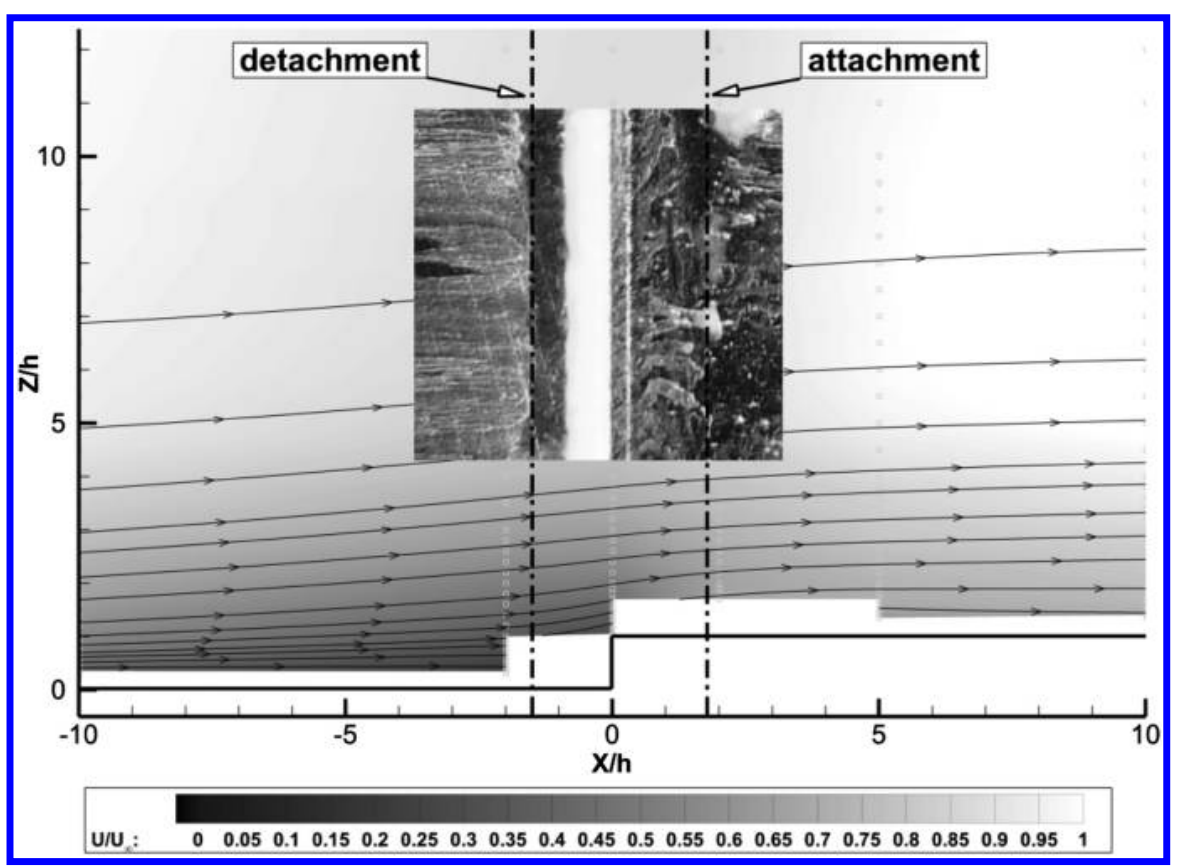

Fig. 27 LDV 2C results at $M_{0}=1.3$ : imperfection type 9.

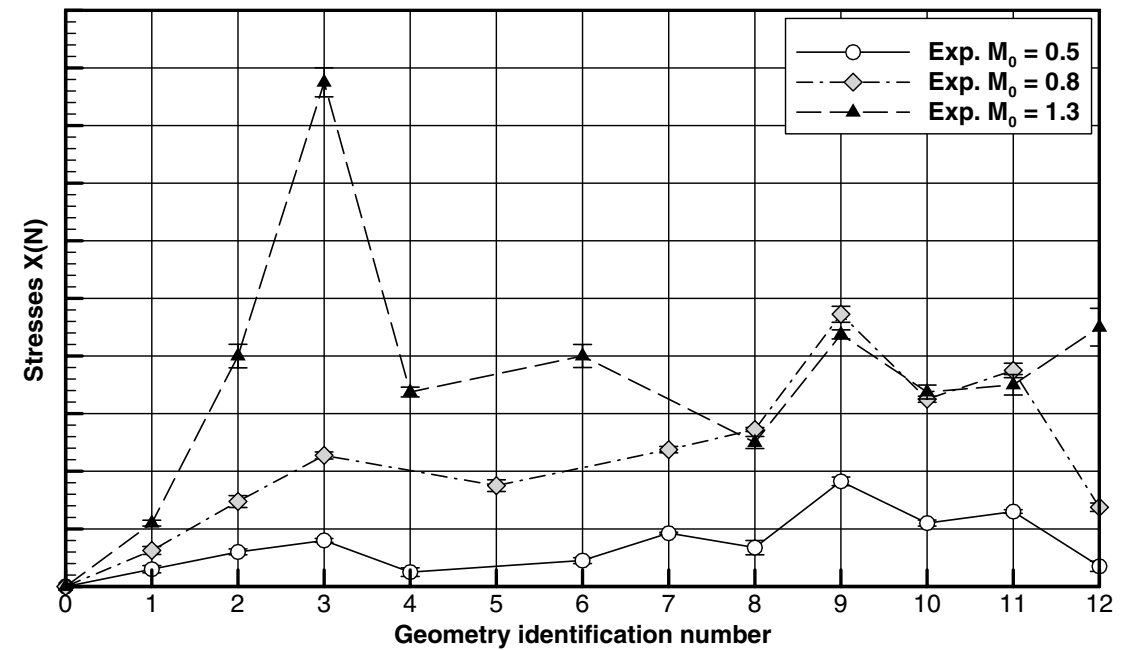

Fig. 28 Experimental stress measurement synthesis at $M_{0}=0.5,0.8$, and 1.3.

\section{Synthesis}

As a synthesis, Fig. 28 presents all the experimental stress measurements for the three Mach numbers. The flat plate (0) and the imperfections $(1,2,3,4,5,6,7,8,9,10,11$, and 12) are considered. For each Mach number, the stress obtained for the flat plate is subtracted from the values obtained for all the geometries so that the additional cost due to an imperfection is clearly visible.

An overall comment concerning Fig. 28 would be that the faster the aircraft is, the more the surface imperfection is costly. This is most noticeable for backward-facing steps. For instance, the imperfection 3 costs less than one unit of force at $M_{0}=0.5$; it costs more than two units at $M_{0}=0.8$ and almost nine units at $M_{0}=1.3$.

However, concerning the forward-facing steps, some imperfections $(8,9,11)$ seem to induce slightly lower drag costs at $M_{0}=1.3$ than they do at $M_{0}=0.8$. This particular behavior of forward-facing steps in supersonic conditions that was observed in the former paragraph (see Fig. 26) is clearly illustrated in Fig. $\underline{28}$.

\section{Conclusions}

This paper focused on the evaluation of the impact of surface imperfections, such as forward-facing and backward-facing plain or chamfered steps, on the drag production of a turbulent flat plate in subsonic, transonic, and supersonic conditions. The results of such investigations are of prime interest to define industrialization tolerances or imperfection shapes offering satisfactory compromises between manufacturing costs and aerodynamic performance.

This study has combined experimental and numerical investigations. A test campaign, involving high-level measurement techniques such as microdrag evaluation, near-wall laser Doppler velocimetry, and oil-film interferometry, has been carried out at three Mach numbers to quantify the impact of a large range of flat-plate imperfections. A whole numerical study has also been completed to be used as a validation/comparison database for the wind-tunnel measurements. It included the realization of structured grids and 2-D RANS calculations using the in-house elsA software on the imperfections studied experimentally.

Globally, given the very small order of magnitude of the forces to be measured and computed, the experimental/numerical comparison is quite satisfactory. Results show an overall good agreement in the relative positioning of most of the imperfection drag productions.

Concerning the subsonic case, experimental and numerical trends are similar. Nevertheless, the experimental drag measurements for forward-facing steps show values much stronger than the numerical ones. 
The same behavior is observed in transonic conditions. The agreement between experimental and numerical sources is still better for backward-facing steps. For this regime, local wind-tunnel and CFD results have been compared. For a typical backward-facing step, comparisons of flow separation extents and skin friction values exhibit very good agreement. On the other hand, for a typical forward-facing step, even if the comparison of flow separation extent predictions is satisfactory, the skin friction evaluations show significant level discrepancies.

In supersonic conditions, a particularly good agreement between computations and experiments is observed. Contrary to the subsonic and transonic cases, this agreement remains good with forwardfacing steps. Indeed, in these conditions, these imperfections do not produce drag levels much larger than the backward-facing steps.

A very interesting outcome of this study concerns the surface imperfection combining backward and forward-facing steps. Indeed, the results obtained with this type of excrescences show that some geometric solutions exhibiting particular shapes (such as cavities instead of steps for instance) can be set to reduce or minimize the impact of surface discontinuities on the aircraft drag.

Another interesting point is that this study has shown how complementary experimental and numerical approaches are. Indeed, when wind-tunnel measurements are impossible or very costly, the CFD methods can sometimes provide the missing data or give access to essential results. For instance, the drag breakdown into pressure and friction components, directly available with the numerical computation, shows that it is mainly the pressure drag that determines the relative positioning of one imperfection in terms of drag production.

Finally, to dispel the doubts concerning the discrepancies observed between the numerical and experimental approaches for the forwardfacing steps in subsonic and transonic conditions, new experiments and more advanced CFD investigations involving 3-D large-eddy simulation or direct numerical simulation computations would be interesting.

\section{Acknowledgments}

The study presented here has been completed in the framework of a research project supervised by the French governmental agency Direction Générale de L'Armement (DGA) in collaboration with Dassault Aviation. The authors would also like to thank the ONERA team of the wind tunnel S8Ch.

\section{References}

[1] Blumer, C. B., and Va, E. E. R., "Boundary-Layer Transition at Supersonic Speeds: Roughness Effects with Heat Transfer," AIAA Journal, Vol. 6, No. 4, 1968, pp. 603-607. doi: $10.2514 / 3.4551$

[2] Al-Maaitah, A. A., Nayfeh, A. H., and Ragab, S. A., "Effect of Suction on the Stability of Subsonic Flows over Smooth Backward-Facing Steps," AIAA Journal, Vol. 28, No. 11, 1990, pp. 1916-1924. doi:10.2514/3.10499

[3] Rothenflue, J. A., and King, P. I., "Vortex Development over Flat Plate Riblets in a Transitioning Boundary Layer," AIAA Journal, Vol. 33, No. 8, 1995, pp. 1525-1526. doi: $10.2514 / 3.12579$

[4] Radeztsky, R. H., Reibert, M. S., and Saric, W. S., "Effect of Isolated Micron-Sized Roughness on Transition in Swept-Wing Flows," AIAA Journal, Vol. 37, No. 11, 1999, pp. 1370-1377. doi:10.2514/2.635

[5] Ladd, D. M., Rohr, J. J., Reidy, L. W., and Hendrickes, E. W., "The Effect of Riblets on Laminar to Turbulent Transition," Experiments in Fluids, Vol. 14, Nos. 1-2, 1993, pp. 1-9. doi:10.1007/BF00196981

[6] Hoerner, S. F., "Fluid-Dynamic Drag: Practical Information on Aerodynamics Drag and Hydrodynamic Resistance," Hoerner Fluid Dynamics, Vancouver, 1965.
[7] Higazy, M. G., and Cockrell, D. J., "The Measurements of Drag Resulting from Small Surface Irregularities Immersed in Turbulent Boundary Layers," Experiments in Fluids, Vol. 2, No. 4, 1984, pp. 197 202. doi:10.1007/BF00571865

[8] Modarress, D., and Johnson, D. A., "Investigation of Turbulent Boundary-Layer Separation Using Laser Velocimetry," AIAA Journal, Vol. 17, No. 7, 1979, pp. 747-752. doi: $10.2514 / 3.61213$

[9] Micheli, F., Losfeld, G., Rouvière, M., and Plantier, G., "Measurements by Laser Doppler Velocimetry at $50 \mu \mathrm{m}$ from a Wall," ONERA TP2004-209, Sept. 2004

[10] Micheli, F., Lavieille, M., and Millan, P., "ASSA, a Reference Tool for the Signal Treatment in Laser Velocimetry," ONERA TP-2007-09, Sept. 2006.

[11] Tanner, L. H., and Blows, L. G., "A Study of Motion of Oil Films on Surfaces in Air Flow with Application to the Measurement of Skin Friction," Journal of Physics E: Scientific Instruments, Vol. 9, No. 3, 1976, pp. 194-202. doi:10.1088/0022-3735/9/3/015

[12] Squire, L. C., "The Motion of a Thin Oil Sheet Under the Steady Boundary Layer on a Body," Journal of Fluid Mechanics, Vol. 11, No. 2, Sept. 1961, pp. 161-179. doi:10.1017/S0022112061000445

[13] Desse, J. M., "Oil-Film Interferometry Skin-Friction Measurement Under White Light," AIAA Journal, Vol. 41, No. 12, 2003, pp. 24682477. doi: $10.2514 / 2.6846$

[14] Le Sant, Y., "Afix 2: An Image Processing Software for Wind Tunnel Applications," ONERA-The French Aerospace Lab TR 211/05458 DAFE, Châtillon, France, 2001.

[15] Le Sant, Y., "Image Processing Tools Applied to Wind Tunnel Testing," Proceedings of the 48th Annual CASI Conference, Toronto, AprilMay 2001.

[16] Pailhas, G., and Barricau, P., "Mesure du Frottement Dans un Écoulement Soumis à un Fort Gradient de Pression Positif-Technique de la Goutte d'Huile," ONERA-The French Aerospace Lab TR 1/ 11524 DMAE, Châtillon, France, Jan. 2007.

[17] Coquet, T., "Mesures de Frottement par film d'Huile. Théories et Incertitudes," ONERA-The French Aerospace Lab, Châtillon, France, 2011.

[18] Zilliac, G. G., "Further Developments of the Fringe-Imaging Skin Friction Technique," NASA, 1996.

[19] Naughton, J. W., and Brown, J. L., "Uncertainty Analysis for Oil-Film Interferometry Skin-Friction Measurement Techniques," American Society of Mechanical Engineers Paper FEDSM97-3475, New York, 1997.

[20] Clauser, F. H., "The Turbulent Boundary Layer," Advances in Applied Mechanics, Vol. 4, 1956, pp. 1-51. doi:10.1016/S0065-2156(08)70370-3

[21] Michel, R., "Couche Limite, Frottement et Transfert de Chaleur," 1967.

[22] Cambier, L., and Gazaix, M., "elsA: An Efficient Object-Oriented Solution to CFD Complexity," 40th AIAA Aerospace Sciences Meeting and Exhibit, AIAA Paper 2002-0108, Jan. 2002.

[23] Cambier, L., Heib, S., and Plot, S., "The ONERA elsA CFD Software: Input from Research and Feedback from Industry," Mechanics and Industry, Vol. 14, No. 3, 2013, pp. 159-174. doi: $10.1051 / \mathrm{meca} / 2013056$

[24] Jameson, A., Schmidt, W., and Turkel, E., "Numerical Solution of the Euler Equations by Finite Volume Methods Using Runge Kutta Time Stepping Schemes," 14th Fluid and Plasma Dynamics Conference, AIAA Paper 1981-1259, June 1981.

[25] Spalart, P. R., and Allmaras, S. R., "A One-Equation Turbulence Model for Aerodynamic Flows," 30th Aerospace Sciences Meeting and Exhibit, AIAA Paper 1992-0439, Jan. 1992.

[26] Menter, F. R., "Zonal Two Equation $k-\omega$ Turbulence Models for Aerodynamic Flows," 23rd Fluid Dynamics, Plasmadynamics, and Lasers Conference, AIAA Paper 1993-2906, July 1993.

[27] Gaudet, L., and Winter, K., "Measurements of the Drag of Some Characteristic Aircraft Excrescences Immersed in Turbulent Boundary Layers," Royal Aircraft Establishment Tech Memo Aero 1538, Bedford, England, U.K., 1973; also AGARD CP-124. 